\title{
A comparative study on the design of an environmentally friendly RoPax ferry using CFD
}

\author{
Herman Peder Kavli, Elif Oguz*, Tahsin Tezdogan \\ Department of Naval Architecture, Ocean and Marine Engineering, Henry Dyer Building, University \\ of Strathclyde, 100 Montrose Street, Glasgow, G4 0LZ, UK \\ * Corresponding author; e-mail: e.oguz@strath.ac.uk, phone: +44(0)1415484047
}

\begin{abstract}
RoPax ferries are designed for maximum efficiency, enabling smooth loading and unloading of cars, cargo and passengers. When optimising successful RoPax design, a compromise is always made between a light and compact hull geometry with diminished power requirement whilst providing substantial car and passenger capacities.

In response to recent computational developments, Computational Fluid Dynamics (CFD) is a widelyused design tool amongst naval architects owing to its more accurate results compared to conventional potential flow theory based techniques. By combining CFD tools with Computer Aided Design (CAD) software, it is possible to obtain useful results at an early stage of a typical ship design process.

The key objective of this paper is to design an environmentally friendly RoPax ferry utilising CAD and CFD tools. This aim was achieved by developing a new RoPax design with a new green power plant configuration releasing less greenhouse gas (GHG) emissions to the atmosphere. The performance of the green power plant was assessed through making a comparison to other power plant options. It is clearly shown in the paper that the hybrid LNG turbine is the most environmentallyfriendly power option amongst the two other power plants investigated in this piece of research.
\end{abstract}

Keywords: RoPax Ferry, GHG emissions, hybrid power plant, ship design, CFD

\section{Introduction}

As the focus on the environmental operation of commercial ships increases, naval architects and ship builders are seeking ways to build and operate more environmentally friendly ships. Sustainment of the shipping industry in response to progressively stringent emission controls, has been at the forefront of technological development for many years, particularly regarding the evolvement of current marine prime movers, or the integration of alternate fuels which emit diminished volumes of harmful substances. The International Maritime Organisation (IMO) enhanced this process by introducing a revised version of the MARPOL Annex VI regulations (2014). These regulations require oil 
companies and engine manufacturers to follow certain guidelines, in order to limit the $\mathrm{SO}_{\mathrm{x}}$ and $\mathrm{NO}_{\mathrm{x}}$ emissions. The limitations on $\mathrm{NO}_{\mathrm{x}}$ emissions, commonly referred to as Tier III criteria, became effective as of $1^{\text {st }}$ January 2016, and apply to ships operating in the Emissions Control Areas (ECAs) of North America and United States Caribbean Sea, particularly to engines installed after $1^{\text {st }}$ January 2016 with a power output greater than $129 \mathrm{~kW}$. Similarly, the $\mathrm{SO}_{\mathrm{x}}$ regulations became effective as of $1^{\text {st January }} 2015$ (IMO, 2014).

DNV GL is also pushing the marine industry in an environmentally friendly direction, by actively taking part in research projects by providing both funding and human resources. DNV GL published a report in 2015 where they stated that "the future is hybrid", and promoted the usage of batteries as a viable solution to reduce emissions from the marine industry. The report concluded with a $14 \%$ reduction in fuel consumption when using hybrid configurations (DNV GL, 2015a).

The Danish/German based ferry operator Scandlines AG is a company that currently owns the largest fleet of hybrid ferries in the world. The fleet of 5 ferries, operating on shorter voyages (1-3 hours), have proven to reduce $\mathrm{CO}_{2}$ emissions by $15 \%$ (Hand, 2015).

Using cleaner fuel, such as LNG, as an alternative to diesel has become more common during the last decade. According to the DNV GL's report (2015b), there are currently around 150 LNG fuelled ships either in operation or on order worldwide. With DNV GL as a project partner, MS Helgoland was built in 2015. The $83 \mathrm{~m}$ long ferry was fitted with LNG engines which reduced $\mathrm{CO}_{2}$ emissions by $20 \%$, $\mathrm{NO}_{\mathrm{x}}$ emissions by $90 \%$ and $\mathrm{SO}_{\mathrm{x}}$ emissions by $95 \%$, as well as eliminating particulate matter emissions (DNV GL, 2015b).

The possibility of using alternatives to the traditional diesel engines for power production has also been a topic of increasing interest. GTT, CMA and its subsidiary CMA Ships and DNV GL (2015), jointly studied the technical design and economic feasibility for an electric-driven 20,000 TEU ULCV container ship to utilise an LNG-fuelled combined cycle gas and steam turbine (COGAS) power plant. The study concluded with LNG fuelled COGAS power generation as the most efficient and economical way of converting fuel into mechanical power or electricity, as they can achieve overall efficiencies and power to weight ratios far beyond traditional diesel engines.

According to IMO's official database of ships (Global Integrated Shipping Information SystemGISIS), there are 633 RoPax ferries of more than 10000 gross tonnage (GT) currently in service, but only $44.2 \%$ and $19.1 \%$ of them were built after 1996 and 2006, respectively. These numbers suggest that the majority of the global fleet of RoPax ferries are old, and were built at a time with low oil prices and little focus on the environment. These figures along with a rising interest in global warming and climate change issues, have encouraged a new generation of environmentally friendly RoPax ferries. 
With this in mind, this study presents a new design of an environmentally friendly RoPax ferry by combining CAD and CFD software packages. This aim was achieved through creating a new ferry design with a selection of green power plant configurations to propel the ferry. Fully nonlinear unsteady Reynolds-Averaged Navier Stokes (RANS) simulations were carried out to obtain the ship resistance versus speed curve of the vessel to predict the ferry's power requirements and hence fuel consumption and emissions for a range of forward speeds. Using the results obtained from CFD, three different power plant configurations for the ferry were investigated and the emissions for each individual power plant installation were predicted based on a predetermined operational scenario. To the best of our knowledge, no specific study exists which aims to investigate the possible benefits for a RoPax ferry to utilise a combination of two of the most environmentally friendly power configurations - a hybrid version of LNG fuelled COGAS power generation system. This study therefore may be useful to understand the operational emissions of the above power generation system by comparing its emissions to those from other power plant configurations installed on the same ferry. In addition, during our literature review (given in sub-section 2.1), it was seen that although significant previous research has investigated the motions, resistance and added resistance of a ship using CFD, no specific study exists which aims to directly estimate the GHG emissions of the vessel due to its operation using a CFD-based RANS technique.

\subsection{A typical ship design process}

The design process adopted in this study, aiming towards obtaining a vessel with reduced emissions, is depicted in Figure 1. The goal of the design process is to reduce the operational emissions by designing a ship that is compact and can carry many vehicles and passengers relative to its size.

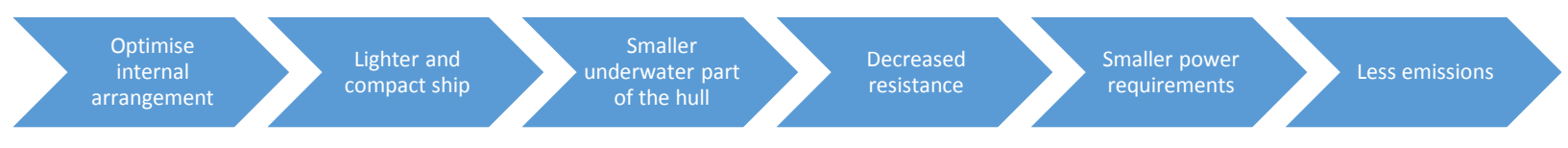

Figure 1 Reduced emissions by hull optimisation

The key to obtain lower operational emissions by design optimisation is to optimise the internal arrangement of the ship in such a way that the ship becomes lighter and more compact. It is important that the ship maintains its cargo capacity during this process, which in this case is passengers and vehicles. This in turn causes a reduction in total resistance and hence less power requirements and therefore lower emissions.

CAD and CFD software packages are important design tools implemented in this part of the study. The CAD software will be used to design a ship geometry that will then be imported into the CFD software which will be used to measure the resistance characteristics of the vessel against speed. This will then enable determination of the power vs speed curve of the vessel in question. 
On the basis of the CAD model, a general arrangement (GA) drawing specifying the passenger and vehicle capacity will be developed. A comparison of similar vessels in terms of capacity and power requirements will be used as a basis to measure the performance of the new ship geometry developed in this paper.

\subsection{Green power plant selection}

The goal of the power plant selection is to reduce the emissions of the ship. This means that the power plant needs to be efficient and yield relatively small emissions per $\mathrm{kWh}$ power output. It is worth noting that the power plant needs to be able to fulfil the IMO MARPOL Annex VI emission criteria (IMO, 2014).

The power plant selection is of great importance in order to reduce the overall emissions from the ship. Whereas the ship geometry determines how much power is required to propel the vessel, the power plant selection determines the level of emissions per power unit used. This paper will focus on new power plant technology and the use of alternative types of fuel in order to formulate a power plant configuration that is purposely designed for reduced emissions.

The power vs speed curve obtained from the CFD analyses will be the basis of the power plant selection. Multiple power plants will be compared to each other in order to make a validated selection, and emission calculations will be the main factor for the final power plant selection.

This paper is organised as follows. Section 2 gives a brief literature review on emissions and CFD studies on hull optimisation. Afterwards, the main dimensions of the ship and the properties of the other comparison cases are given. Following this, the numerical setup of the CFD model is presented. Then, all of the results from this work are discussed in detail. Finally, a brief summary of the main results from this work are provided in Section 5 and suggestions are made for future study.

\section{Background}

RoPax ferries are a combination of RoRo ferries and passenger ferries. RoRo ferries are built for transporting vehicles that can "roll on and roll off" whereas passenger ferries are built for transporting passengers. As a RoPax ferry is a combination of the two, they are designed to transport both vehicles and passengers. According to ShipPax, RoPax ferries transported more than 1.3 billion passengers and 217.5 million vehicles on 5.9 million global crossings in 2004 (Zagkas and Pratikakis, 2012).

\subsection{Literature survey}

As stated in Tezdogan et al. (2016), CFD is a commonly used design tool among naval architects and marine engineers due to its significant advantages over potential flow theory based methods. The application of such techniques to determine the performance and behaviour of ships allows designers 
to assess hydrodynamic performance at the early design stage enabling any necessary corrective action to be taken before the ship is actually built. Tezdogan et al. (2015) reviewed the latest CFD applications in the marine industry in the literature review section of their article.

There are many CFD studies on ship hull optimisation. To cite an example from the published literature, Percievel et al. (2001) carried out a study in order to optimise a hull form for minimum calm-water resistance using a CFD method. Campana et al. (2006) used CFD analysis to optimise the bow shape of a ship hull. Besnard et al. (2007) carried out a study on hull shape optimisation of a fast ship using CFD and structural analysis. Around the same time, Vyselaar et al. (2007) investigated the effect of parabolic bulbs on ship resistance. They applied the parabolisation technique to a high-speed NPL trimaran. In their study they used a Rankine source panel method to obtain the wave-making resistance and a RANS solver together with an Integral Boundary Layer solver to predict the viscous drag of the trimaran. Their numerical results supported by experimental studies showed that the trimaran hull with appended parabolic side bulbs reduced the total resistance by up to $6 \%$. Following this, He et al. (2011) adopted metamodeling to a multidisciplinary design optimisation process of a ship hull from resistance, seakeeping and manoeuvring standpoints. In their ship hull optimisation process they used the FLUENT software as a RANS solver to predict the resistance of a vessel. They developed an automated process to run the CFD simulations in a relatively short time. Later, Guo et al. (2013) investigated the resistance and wave pattern of the KVLCC2 ship by conducting a series of numerical and experimental studies. They used the ISIS-CFD tool, developed by EMN, to solve the RANS equations. In their study, they focused on resistance distribution along the ship hull which was divided into three segments. They also performed a verification study and compared their CFD results to those from experiments they conducted at MARINTEK.

A CFD method is extensively used in many research studies aiming to reduce total resistance for more efficient vessels. For example, Kim et al. (2014) recently emphasised the importance of the accurate prediction of ship resistance and added resistance due to waves for accurate calculation of an Energy Efficiency Design Index (EEDI). In their study they performed a numerical study to predict the added resistance of a KCS model advancing in regular head seas using CFD. They reported that their simulation results agree well with the existing experimental data. Following this, Tezdogan et al. (2015) performed CFD simulations to obtain the added resistance of a full-scale KCS model in head seas for typical design and representative slow steaming speeds. They used Star-CCM+ as a RANS solver and revealed the benefits of applying a slow steaming approach as a means of reducing fuel consumption. However, in their study they did not directly calculate the operational emissions from their vessel in question, instead comparing the hydrodynamic performance of the KCS model under two forward speed conditions. More recently, Mizzi et al. (2017) proposed a numerical approach for optimisation of a Propeller Boss Cap Fins (PBCF) using a high fidelity CFD-based RANS method. Their results indicated a net energy efficiency improvement of $1.3 \%$ that can lead to substantial 
reduction of cost and energy consumption. The study also clearly indicated that the best design candidate produced a weakened hub vortex presenting additional benefits for this retrofitting technology. Around a similar time, a research group from the University of Strathclyde, Glasgow as reported in Demirel et al. (2017), proposed a fully nonlinear CFD-based unsteady RANS method to model the roughness effects of marine coatings and biofouling on the resistance of a full-scale ship hull. Their approach can be regarded as an alternative method to the traditional similarity law scaling procedure, which uses the flat plate approach. Their analyses stated that, due to heavy slime fouling the increase in the effective power of the full-scale KCS model could be up to $38 \%$ at the ship design speed (24 knots).

CFD simulations have also been used to study different engineering options for more fuel-efficient ships. For example, Hochkirch and Bertram (2010) summarised technical levers to save fuel and reduce emissions from ships. In addition, Kilpinen (2010) developed an accurate and complete CFDbased marine diesel engine modelling to predict NO emissions from a diesel engine. More recently, Ammar and Farag (2016) numerically studied the combustion and emission characteristics of syngas fuel in marine gas turbines. They performed their analyses using the ANSYS FLUENT software under various operational conditions. They also compared the $\mathrm{CO}_{2}, \mathrm{CO}$ and $\mathrm{NO}$ emissions from syngas and natural gas fuel combustion.

Today, Heavy Fuel Oil (HFO) remains the most popular fuelling option for ship propulsion, harnessing its potential in diesel engines due to their high thermal efficiency. However, diesel engines are not the optimal solution considering the emissions they expel, a factor subject to exceeding scrutiny, and one which forms the basis for the diversification of marine fuelling current underway. These factors have led the shipping industry to question whether this present mode of ship propulsion is sustainable, where increases to both operating costs and emission volumes have forced the industry to look for ways to innovate, implement and improve current propulsion methods, in order to benefit the environment.

There are various power plant configurations that can be utilised, depending on the requirements of the ship. The following sections will introduce the different configurations that have been considered in this study.

\subsection{Conventional propulsion configurations}

Conventional propulsion configurations are the most commonly used ones for RoPax ferries, as they are cheap and easy to install. However, it is undecided whether they are the best option for RoPax vessels, as they have a fluctuating service pattern in terms of speed and power usage. 


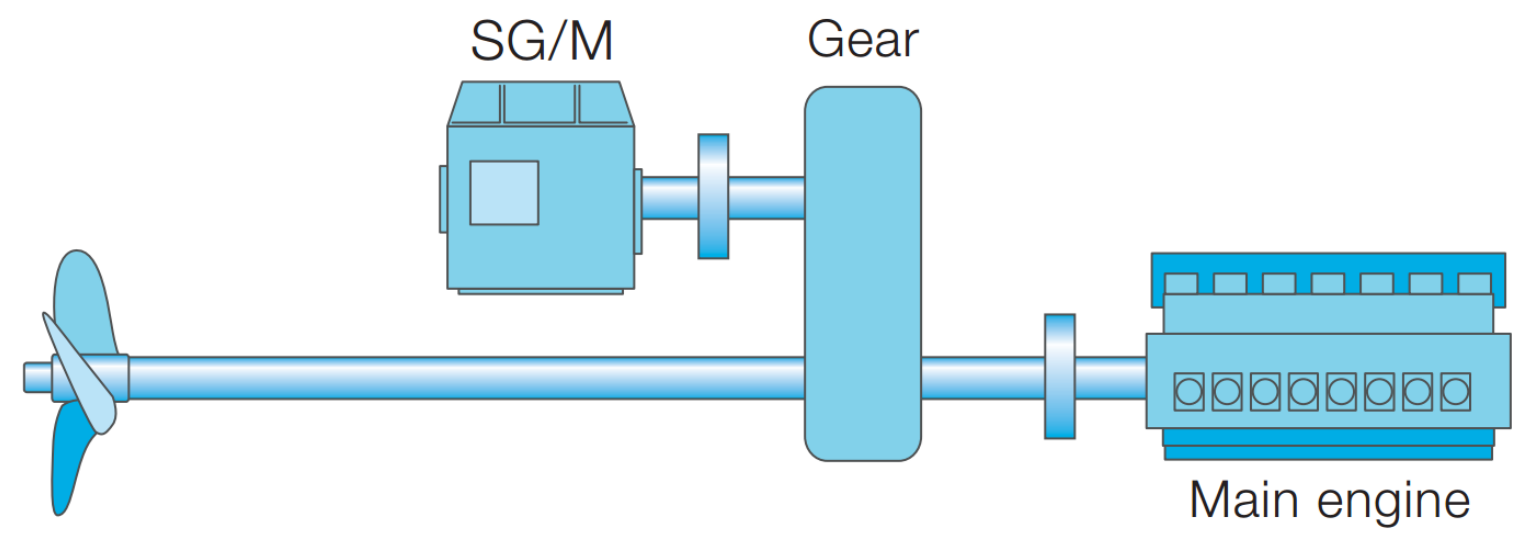

Figure 2 Conventional propulsion system (ABB, 2014)

Conventional propulsion configurations, as illustrated in Figure 2, generally use one or more large main engines that are connected directly to the aft propellers via a gearbox. The on-board electricity usage is produced by a shaft generator (SG) or auxiliary generators. The configuration has a good efficiency when operating at service load, as the main engine runs on optimal revolutions per minute (rpm) and brake specific fuel consumption (BSFC) within these circumstances. However, it is when the vessel approaches the port that this configuration displays its weaknesses. The sailing speed is obtained by adjusting the rpm of the main engine. As a consequence of the rpm adjustment, the engine operates outside of its optimal rpm and BSFC region, which results in increased emissions when the vessel is in the port. The smaller auxiliary generators that may be used while in the port are generally less efficient than bigger engines, which contributes to poor performance in terms of emissions while the vessel is in the port.

Another drawback of this configuration is the mechanical connection (shaft) between the main engine and the propellers, which takes up a large space. A single engine failure in this configuration can cause partial or full power shutdown.

\subsection{Electric propulsion configurations}

Electric propulsion systems are becoming more common, especially in the offshore industry. This is due to the highly flexible service pattern that this configuration offers. 


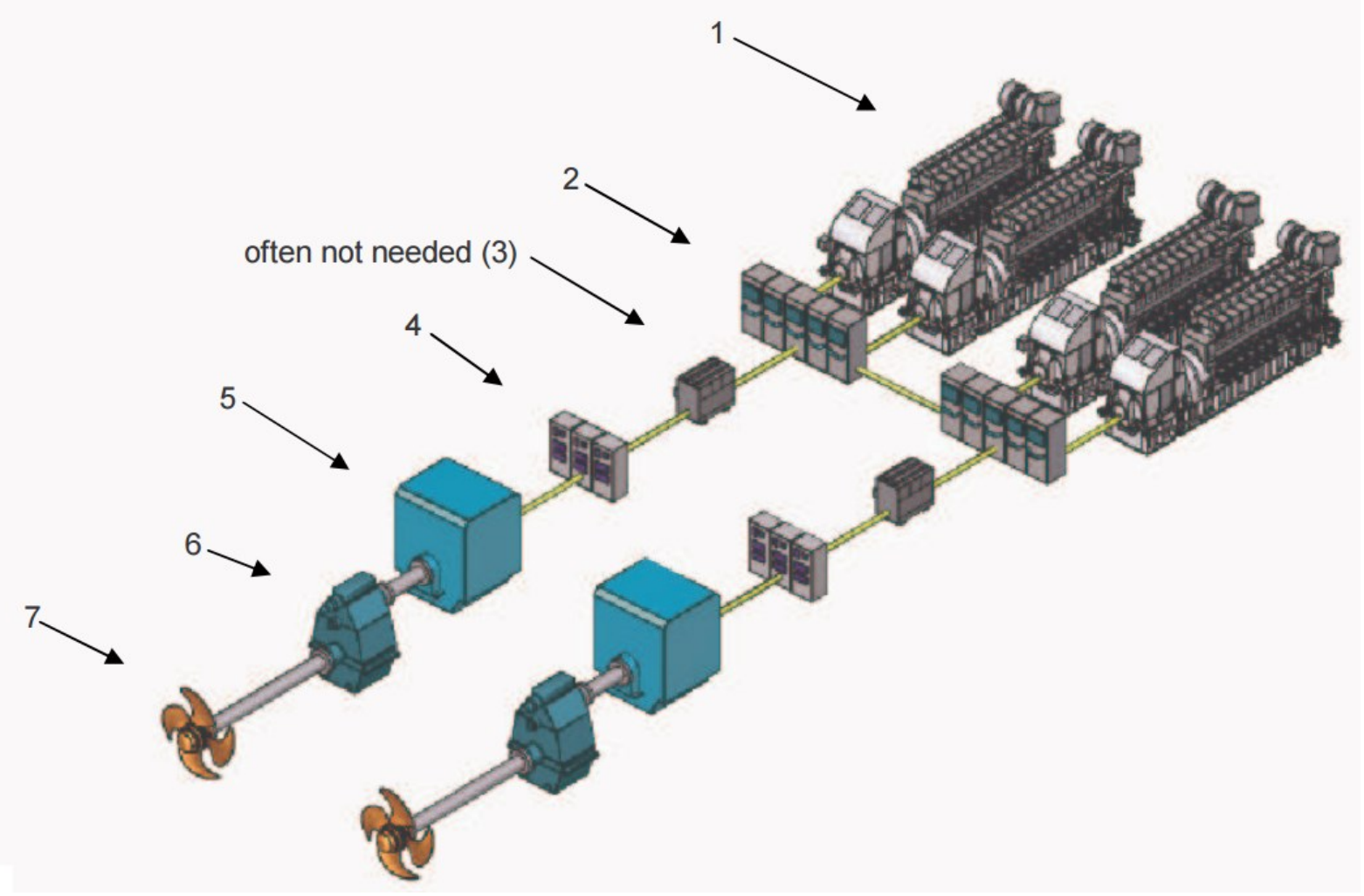

Figure 3 General configuration of diesel-electric propulsion plant (MAN Diesel, n.d.)

Table 1 Legend summary of Figure 3 (MAN Diesel, n.d.)

\begin{tabular}{|c|l|}
\hline Item & Contents \\
\hline 1 & Gensets: Diesel engines + alternators \\
\hline 2 & Main switchboards \\
\hline 3 & Supply transformer (optional) \\
\hline 4 & Frequency converters \\
\hline 5 & Electric propulsion motors \\
\hline 6 & Gearboxes (optional) \\
\hline 7 & Propellers \\
\hline
\end{tabular}

Rather than having a few large main engines, this configuration includes more, but smaller, main engines that are directly connected to a generator, commonly referred to as gensets. The type and number of main engines is determined depending on the design criteria of the ship. The focus in this study will be on diesel engines and liquefied natural gas (LNG) fuelled turbines to be used as main engines.

The gensets have one specific job only - to produce electricity. The propellers are driven by electric motors, which are powered by the electricity produced by the gensets. This means that the mechanical power produced by the main engines is converted into electrical power, and then back to mechanical power to rotate the propellers. As Figure 3 shows, there are many components between the main engines and the propellers to support this conversion. The numbered items in Figure 3 are explained in 
Table 1. It is not relevant to this study to delve deeper into the technical details of all the components involved, but it is important to understand the overall functionality of the configuration.

The switchboard is the heart of the configuration, as every on-board electric unit is connected to it. The switchboard also acts like the brain of the configuration, signalling the gensets to start or stop depending on how much power is needed at a given time. This means that the configuration regulates the sailing speed by adjusting the number of simultaneously running gensets rather than adjusting the rpm of the engines. This allows the gensets to operate at their optimal rpm and BSFC most of the time.

Because the gensets and propulsion units are connected via electrical wires, they can be installed almost everywhere in the ship, allowing a more flexible design. The configuration is also a lot more reliable, as the power output will not be extensively affected by the failure of a main engine.

Because there are more components involved, the overall efficiency may be lower than for the conventional configurations. Typical losses in a diesel-electric propulsion plant are shown in Figure 4.

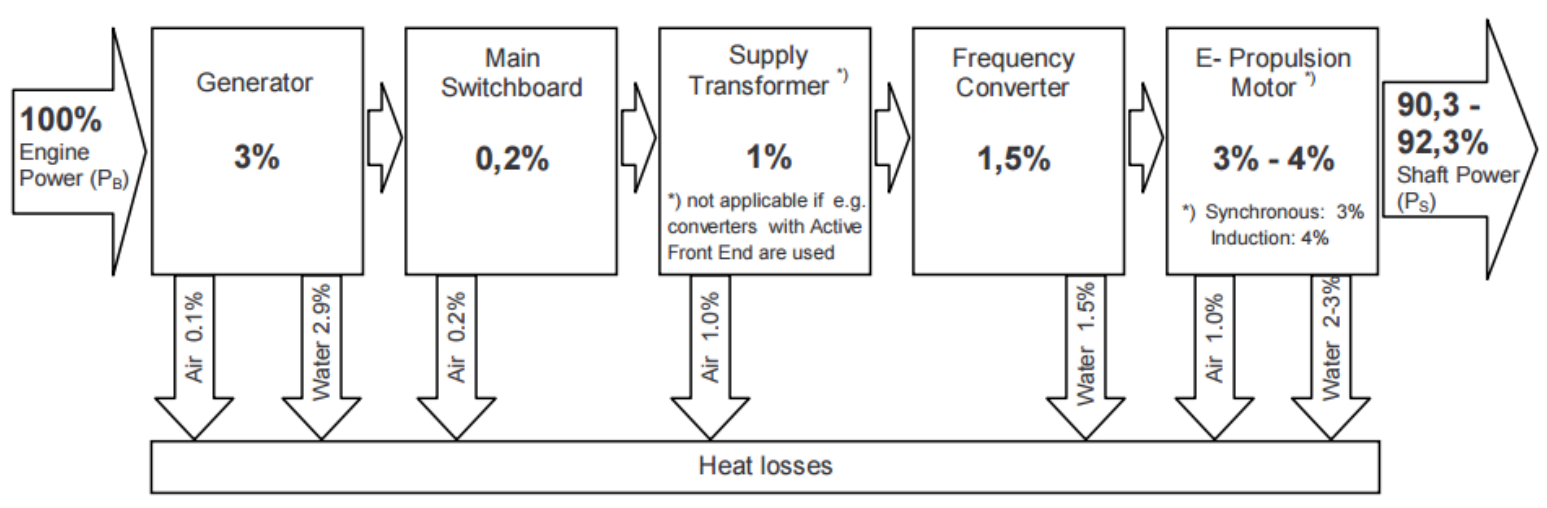

Figure 4 Efficiencies in diesel-electric plants (MAN Diesel, n.d.)

\subsection{Hybrid configurations}

Hybrid configurations utilise the same components as the electric propulsion configurations, but batteries are also added to the circuit. The batteries are charged by the gensets in order to store energy that can be used to cover short periods of time when extra large or small amounts of power are required.

This configuration also allows the ship to operate solely on electricity for short periods, which can be very beneficial in terms of emissions, especially when the ship is operating in or near the port.

\subsection{Emission of Greenhouse Gases (GHG)}

A report by the IMO shows that the international shipping industry emitted $2.2 \%, 30 \%$ and $9 \%$ of the global $\mathrm{CO}_{2}, \mathrm{NO}_{\mathrm{x}}$ and $\mathrm{SO}_{\mathrm{x}}$ emissions, respectively, in 2012 (IMO, 2014). In order to control gaseous emissions and air pollution as well as to reduce the environmental impact of the maritime industry, 
several international and national regulatory bodies such as the IMO, European Maritime Safety Agency (EMSA) and Environmental Protection Authority (EPA) have suggested a number of regulations to restrict the non-greenhouse gaseous emissions including $\mathrm{NO}_{\mathrm{x}}$ and $\mathrm{SO}_{\mathrm{x}}$ as well as the greenhouse gaseous emissions, particularly $\mathrm{CO}_{2}$, as reported in IMO (2014), EMSA (2015) and EPA (2010).

Since the container ship sector has relatively large ships sailing at comparatively high speeds which causes high fuel consumption, most of the current efforts to decrease $\mathrm{CO}_{2}$ emissions from global shipping are focused on container ships. Corbett et al. (2009) introduced slower operational speeds in practice referred to as 'slow steaming', which has been shown to significantly reduce fuel consumption and emissions. Later, Lindstad and Sandaas (2016) carried out a study for an offshore support vessel to investigate potential emission and fuel consumption reductions through the introduction of hybrid technologies by taking advantage of their climate mitigation potential. They used four different fuel and engine technologies each with a standard combustion engine and with a hybrid arrangement that included standard combustion engines with batteries in their study. Their results showed that hybrid technologies reduce both fuel consumption and emissions and that the climate impact of the emission reduction is much larger than the fuel reduction alone.

As this work's focus is to design a RoPax ferry with a particularly green power plant, the emissions of greenhouse gases need to be analysed and calculated. There are many different GHG emitted during the combustion of fuel and in order to get accurate calculations of the emission of these, analyses from the actual exhaust is needed. As these analyses are difficult to get hold of, this study has focused on a few of the most important GHG, such as $\mathrm{CO}_{2}, \mathrm{NO}_{\mathrm{x}}, \mathrm{SO}_{\mathrm{x}}$, particulate matter (PM) and hydrocarbons.

\subsection{1 $\mathrm{CO}_{2}$ emissions}

$\mathrm{CO}_{2}$ emissions arise as the fuel is combusted, and the $\mathrm{CO}_{2}$ emissions are a direct function of the fuel consumption. The amount of $\mathrm{CO}_{2}$ produced is dependent on what kind of fuel is used in the combustion process.

Considering global differences in population, economy, land-use and agriculture, a large number of scenarios were developed and modelled by the IMO for the UN IPCC (United Nations Intergovernmental Panel on Climate Change) in order to determine the expected changes in $\mathrm{CO}_{2}$ emissions from shipping from 2007 to 2050 (IMO, 2009).

As reported in Pike et al. (2011), the IMO has intended to improve the shipping sectors' carbon footprint by introducing the Energy Efficiency Design Index (EEDI), the Energy Efficiency Operational Indicator (EEOI) and Ship Energy Efficiency Management Plan (SEEMP). These measures are in force to facilitate the reduction of $\mathrm{CO}_{2}$ emissions, as well as the energy efficiency and fuel consumption throughout a ship's operating lifespan as discussed in Theotokatos and Tzelepis 
(2015). The EEDI was made mandatory for new ships and its standards will be tightened every 5 years from 2015 to 2030 as detailed in Figure 5.

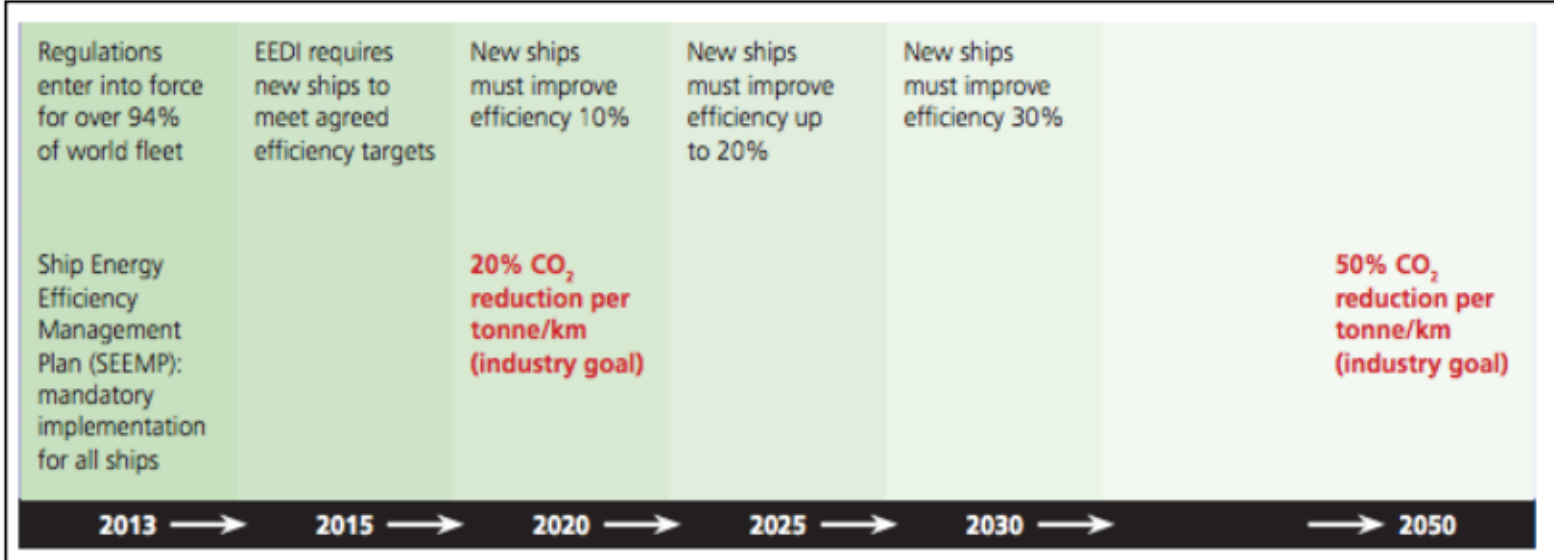

Figure 5 EEDI: MARPOL Annex VI, CO2 Limits (IMO, 2012, ICS, 2014).

\subsection{2 $N O_{x}$ emissions}

$\mathrm{NO}_{\mathrm{x}}$ is the general term for the different types of gases that comprise a mix of nitrogen and oxygen. Two of the most common gases that occur from this mix are nitric oxide (NO) and nitrogen dioxide $\left(\mathrm{NO}_{2}\right)$. The amount of $\mathrm{NO}_{\mathrm{x}}$ produced is dependent on the engine, but can be mechanically limited by the usage of external equipment on the engine, such as selective catalytic reduction units (SRC).

$\mathrm{NO}_{\mathrm{x}}$ emission limits were set by the IMO for diesel engines against the engine maximum operating speed (n [rpm]) as jointly shown in Table 2 and Figure 6. It should be mentioned that Tier III level can only be applied in emission control areas (ECAs) whilst Tier I and Tier II are in force globally.

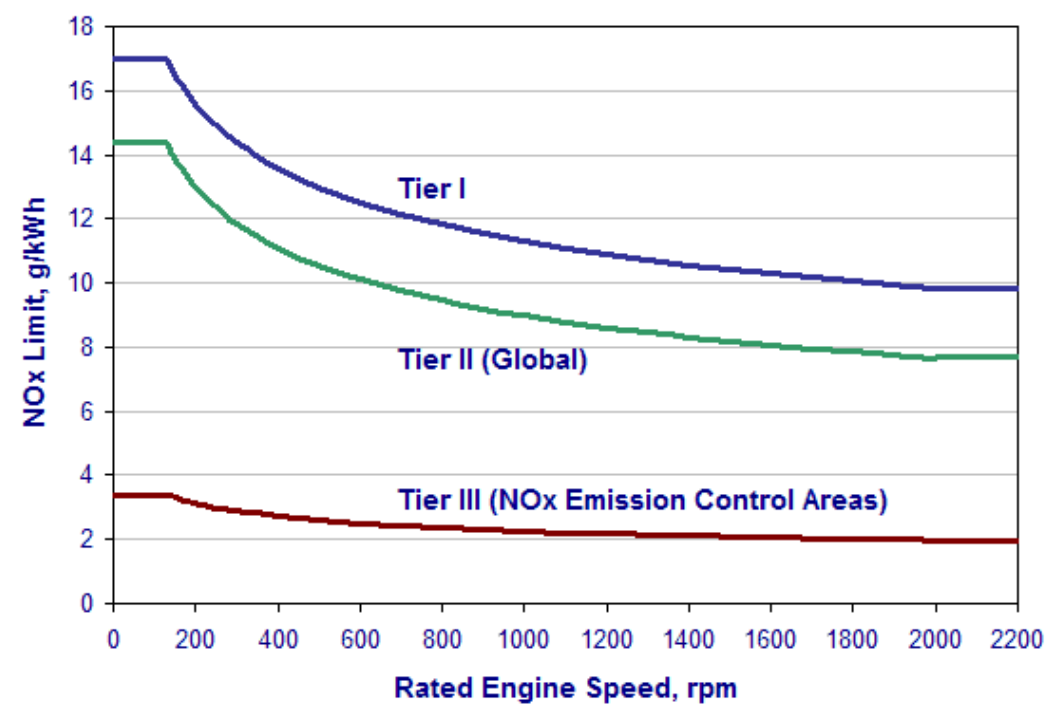

Figure 6 NOx emission limits according to MARPOL Annex VI (IMO, 2014) 
Table 2 MARPOL Annex VI NOx Emission Limits (IMO, 2014)

\begin{tabular}{|l|l|c|c|c|}
\hline & \multirow{2}{*}{ Tier } & \multicolumn{3}{|c|}{ NOx Limit, $\mathbf{g} / \mathbf{k W h}$} \\
\cline { 3 - 5 } & $\mathbf{n}<\mathbf{1 3 0}$ & $\mathbf{1 3 0} \leq \mathbf{n}<\mathbf{2 0 0 0}$ & $\mathbf{n} \geq \mathbf{2 0 0 0}$ \\
\hline Tier I & 2000 & 17.0 & $45 \cdot \mathrm{n}^{-0.2}$ & 9.80 \\
\hline Tier II & 2011 & 14.4 & $44 . \mathrm{n}^{-0.23}$ & 7.70 \\
\hline Tier III & 2016 & 3.4 & $9 \cdot \mathrm{n}^{-0.2}$ & 1.96 \\
\hline
\end{tabular}

\subsection{3 $\mathrm{SO}_{x}$ emissions}

$\mathrm{SO}_{\mathrm{x}}$ is the generic term used for different kinds of oxides of sulfur that occur during the combustion process. The amount of emissions of this pollutant is highly dependent on the fuel type used. The emission of $\mathrm{SO}_{\mathrm{x}}$ can therefore be limited by selecting a fuel with lower amounts of sulfur in it, but can also be limited by installing external equipment that cleans the exhaust from the engines, such as scrubbers (American Berau of Shipping, 2015).

In order to reduce the global $\mathrm{SO}_{\mathrm{x}}$ emissions from the marine industry, the IMO has set limitations on sulfur content in the fuel in the MARPOL Annex VI standards (see Figure 7).

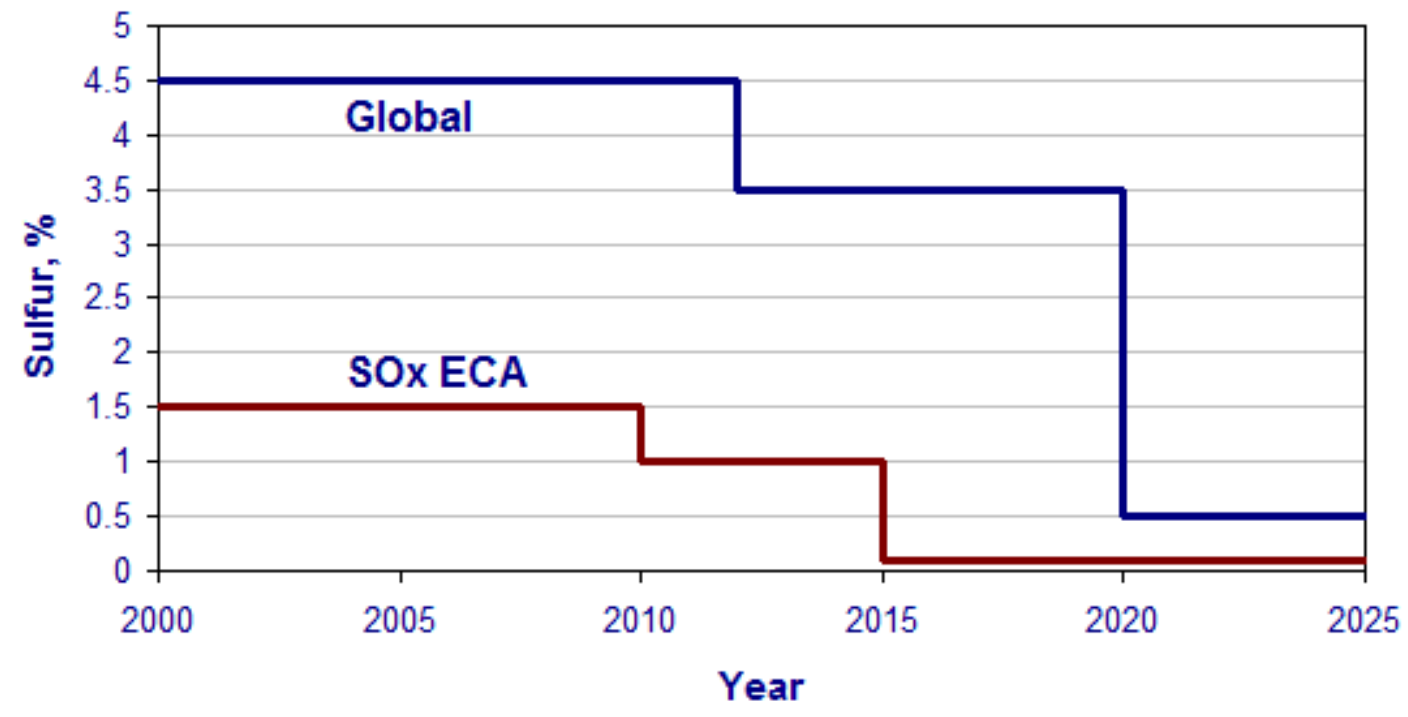

Figure 7 Fuel sulfur limits according to MARPOL Annex VI (IMO, 2014)

\subsubsection{Particulate matter (PM) emissions}

PM emissions are a mix of solid and liquid particles that are emitted with the exhaust. The magnitude of PM emissions is a function of the fuel consumption and the sulfur content in the fuel. In the same way as $\mathrm{SO}_{\mathrm{x}}, \mathrm{PM}$ emissions can be limited by using fuels with a low sulfur content. Depending on the size of the particles, PM can also, in some extend, be limited by the use of external equipment to clean the exhaust, such as scrubbers (American Berau of Shipping, 2015).

MARPOL Annex VI indirectly aims to reduce the emission of PM by limiting the content of sulfur in the fuel, as shown in Figure 7. 


\subsubsection{Hydrocarbon emissions}

Hydrocarbon (HC) emission occurs when unburned or partly burned (slip) fuel is released with the exhaust and into the atmosphere. This study will focus on one specific type of hydrocarbon, namely methane $\left(\mathrm{CH}_{4}\right)$. Preventing methane slip can be challenging, but some scrubbers can limit the emissions. Selecting other type of engines which burn the methane more efficiently, such as turbines, can also limit the HC emissions.

\section{Numerical set-up}

Up to this section, this paper has provided a background to this study and has given an introduction to the work. The following section will present details of the numerical model of the RoPax ferry and will discuss the CFD simulations used in this study.

\subsection{Hull Modelling}

Although most of the RANS resistance simulations were performed in the model scale, Hochkirch and Mallol (2013) reported that model scale flows and full-scale flows can be different due to scale effects. They indicated that these discrepancies stem from different boundary layers, flow separation, and wave breaking. In their paper, Hochkirch and Mallol (2013) showed the importance of modelling at the full-scale using a large number of examples. For this reason, in this study a full-scale ship geometry was modelled using the Maxsurf Modeller CAD tool. The main design parameters of the hull are shown in Table 3.

Table 3 The main particulars of the ferry

\begin{tabular}{|l|l|}
\hline Item & Value \\
\hline Overall length ( $\left.\mathrm{L}_{\mathrm{OA}}\right)$ & $150 \mathrm{~m}$ \\
\hline Length of waterline $\left(\mathrm{L}_{\mathrm{WL}}\right)$ & $150 \mathrm{~m}$ \\
\hline Beam at waterline $\left(\mathrm{B}_{\mathrm{WL}}\right)$ & $24 \mathrm{~m}$ \\
\hline Design draft $(\mathrm{T})$ & $5.5 \mathrm{~m}$ \\
\hline Depth $(\mathrm{D})$ & $7.5 \mathrm{~m}$ \\
\hline Block coefficient $\left(\mathrm{C}_{\mathrm{B}}\right)$ & 0.643 \\
\hline Longitudinal Centre of Gravity (LCG) (from aft peak) & $77 \mathrm{~m}$ \\
\hline Vertical Centre of Gravity $(\mathrm{VCG})$ & $3.5 \mathrm{~m}$ \\
\hline Moment of inertia $\left(\mathrm{K}_{\mathrm{xx}} / \mathrm{B}\right)$ & 0.4 \\
\hline Moment of inertia $\left(\mathrm{K}_{\mathrm{yy}} / \mathrm{L}_{\mathrm{WL}}, \mathrm{K}_{\mathrm{zz}} / \mathrm{L}_{\mathrm{WL}}\right)$ & 0.25 \\
\hline
\end{tabular}

At this early design stage the hull was modelled without bow thrusters or aft propellers. Isometric and side views of the model obtained from Maxsurf are given in Figures 8 and 9, respectively. 


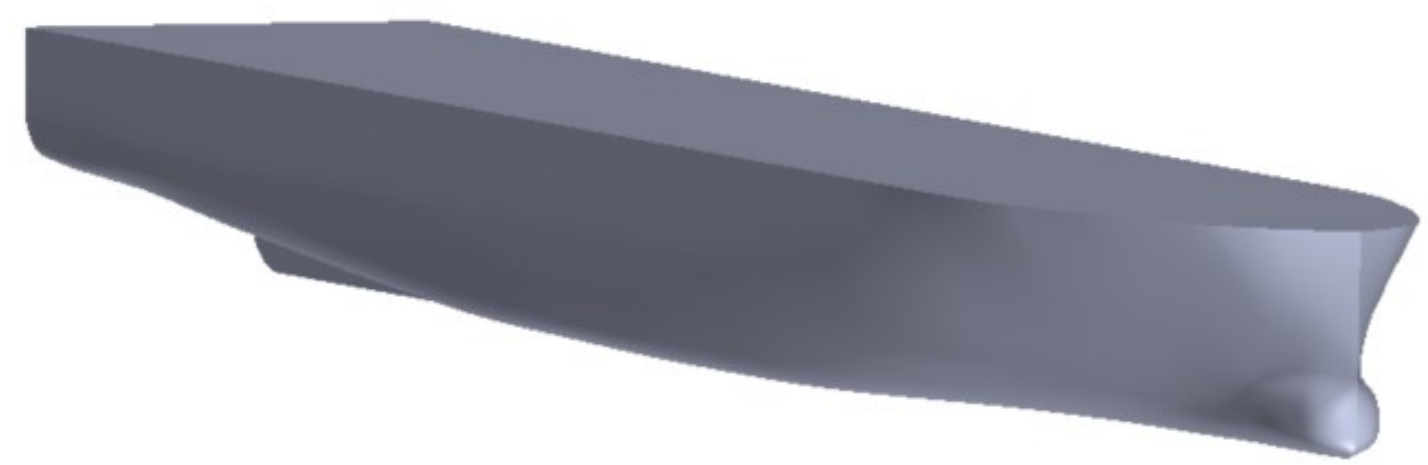

Figure 8 Isometric view of the model obtained from Maxsurf

Figure 9 Side view of the model obtained from Maxsurf

\subsubsection{Wave piercing bow}

As shown in Figure 10, the bow was designed with a wave piercing bow which aims to reduce the wave resistance by piercing through the waves, rather than pushing them away. It was also designed to be vertical, with a relatively small flare angle that reduces the amount of reserve buoyancy at the bow. The lack of reserve buoyancy prevents the vessel from reacting with trim motions when penetrating the waves.

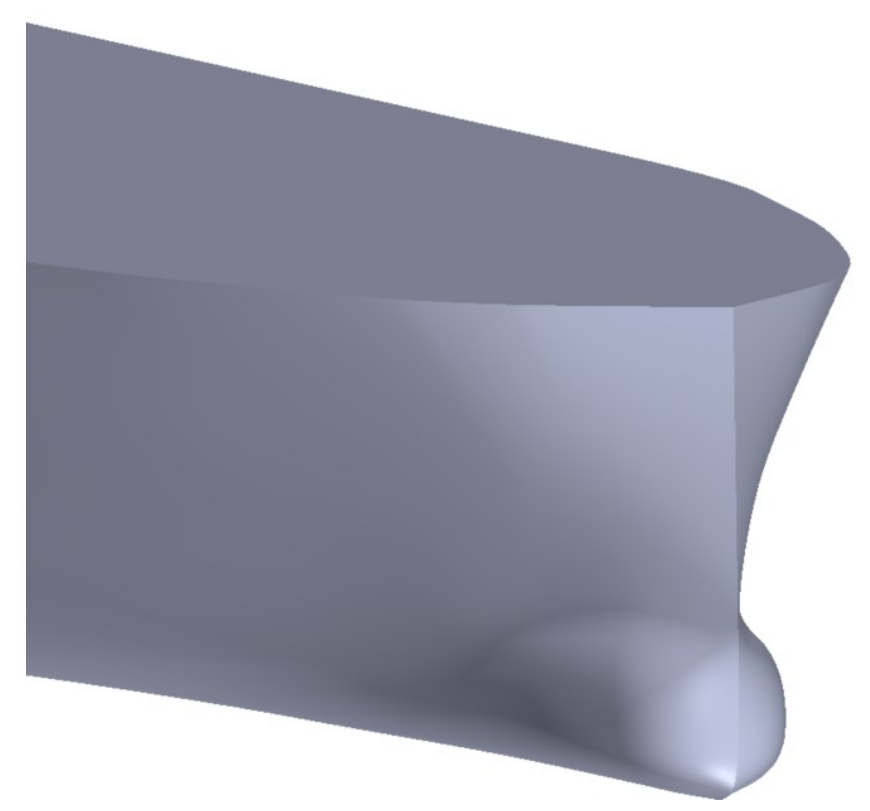

Figure 10 The wave piercing bow of the vessel 


\subsubsection{Flat stern}

The stern was modelled to be flat as given in Figure 11. This was due to the relatively small draft of 5.5 metres, which leaves little space for the aft propellers. It was therefore considered that three propellers were needed in order to obtain enough power for propulsion.

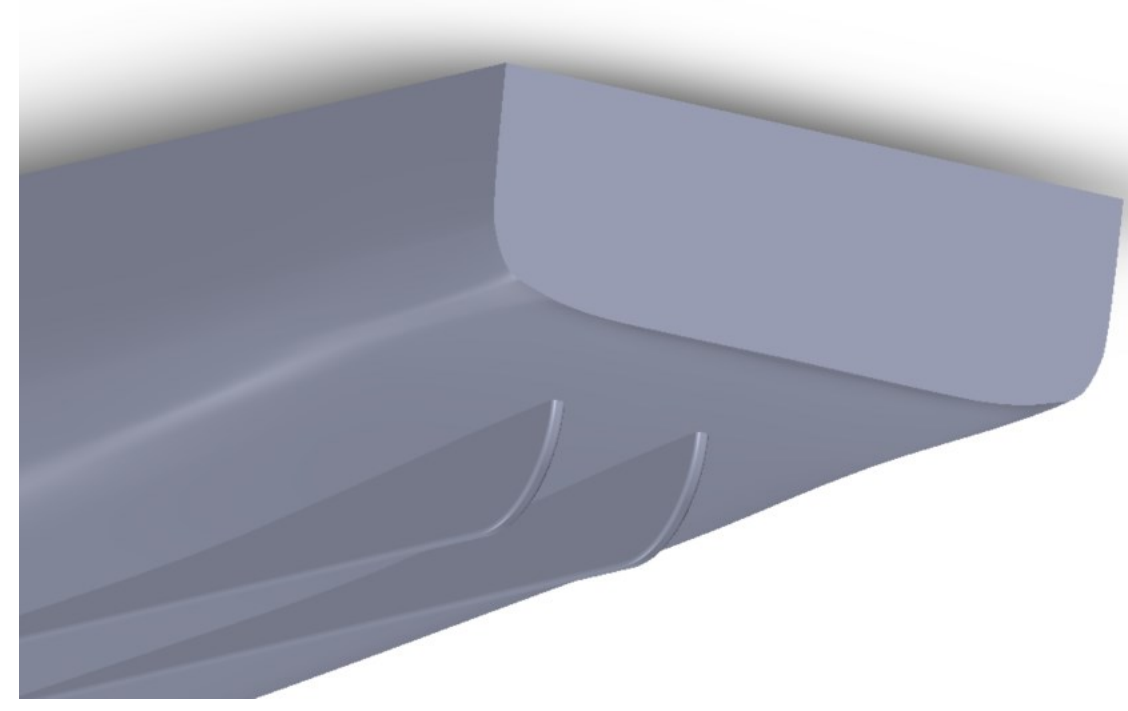

Figure 11 The Flat stern

\subsection{CFD modelling}

In this study, an unsteady RANS approach is applied using the commercial CFD software Star-CCM+ version 11.0.2, which was developed by CD-Adapco (2016). Additionally, the supercomputer facilities at the University of Strathclyde have been utilised to allow much faster and more complex simulations. CFD simulations were performed at five different speeds $(5,18,20,22$ and 24 knots). It is also worth mentioning that in order to simulate realistic ship behaviour, the model was also set free to trim and sink utilising a Dynamic Fluid Body Interaction (DFBI) model.

\subsubsection{Physics modelling}

The turbulence model selected in this study was a standard k- $\varepsilon$ model, which has been extensively used for industrial applications (CD-Adapco, 2016). Also, Querard et al. (2008) note that the k-E model is quite economical in terms of CPU time, compared to, for example, the SST turbulence model, which increases the required CPU time by nearly $25 \%$. The $\mathrm{k}-\varepsilon$ turbulence model has also been used in many other studies performed in the same area, such as Kim and Lee (2011), Enger et al. (2010) and Tezdogan et al. (2015, 2016).

\subsubsection{Choice of the time-step}

The Courant number (CFL), which is the ratio of the physical time step $(\Delta t)$ to the mesh convection time scale, relates the mesh cell dimension $\Delta x$ to the mesh flow speed $U$ as given below: 


$$
C F L=\frac{U \Delta t}{\Delta x}
$$

The Courant number is typically calculated for each cell and should be less than or equal to 1 for numerical stability.

Often, in implicit unsteady simulations, the time step is determined by the flow properties, rather than the Courant number. According to the International Towing Tank Conference (ITTC)'s related guideline, the time-step for resistance simulations in calm water is formulated as $\Delta \mathrm{t}=0.005 \sim 0.01 \mathrm{~L} / \mathrm{U}$, where $\mathrm{L}$ is the length of the ship model and $\mathrm{U}$ is the ship speed (ITTC, 2011). In this work the timestep was selected to be $\Delta \mathrm{t}=0.0075 \mathrm{~L} / \mathrm{U}$.

The maximum number of inner iterations per time-step was set to 10 . This number was considered to be enough for the purpose of this study, as the computational time increases rapidly when increasing the maximum number of inner iterations. It is also worth noting that a first-order temporal scheme was applied to discretise the unsteady term in the Navier-Stokes equations. The stopping criteria of the simulations was set to be 500 physical seconds, and visual convergence lasting more than 30 physical seconds.

\subsubsection{Computational domain}

In all CFD work, the initial and boundary conditions must be selected carefully in order to obtain accurate results within reasonable computational time. For resistance simulations ITTC (2011) recommends that the inlet boundary should be positioned $1-2 L_{B P}$ away from the hull whilst the outlet should be located $3-5 L_{B P}$ downstream in order to prevent any wave reflection from the walls. The dimensions used in this study were selected based on the ITTC's recommendations as well as other pieces of previous work summarised in Table 4. The locations of the boundaries applied in this work's CFD modelling are depicted in Figure 12.

Table 4 The locations of the boundaries in similar previous studies (Tezdogan et al., 2015)

\begin{tabular}{|l|c|c|c|c|c|}
\hline \multirow{2}{*}{ Reference } & \multicolumn{5}{|c|}{ Directions } \\
\cline { 2 - 6 } & Upstream & Downstream & $\mathbf{U}_{\mathbf{p}}$ & Bottom & Transverse \\
\hline Shen and Wan (2012) & $1 L_{B P}$ & $4 L_{B P}$ & $1 L_{B P}$ & $1 L_{B P}$ & $1.5 L_{B P}$ \\
\hline Ozdemir et al. (2014) & $2 L_{B P}$ & $3 L_{B P}$ & $2 L_{B P}$ & $2 L_{B P}$ & $2 L_{B P}$ \\
\hline Simonsen et al. (2013) & $0.6 L_{B P}$ & $2 L_{B P}$ & N/A & N/A & $1.5 L_{B P}$ \\
\hline
\end{tabular}




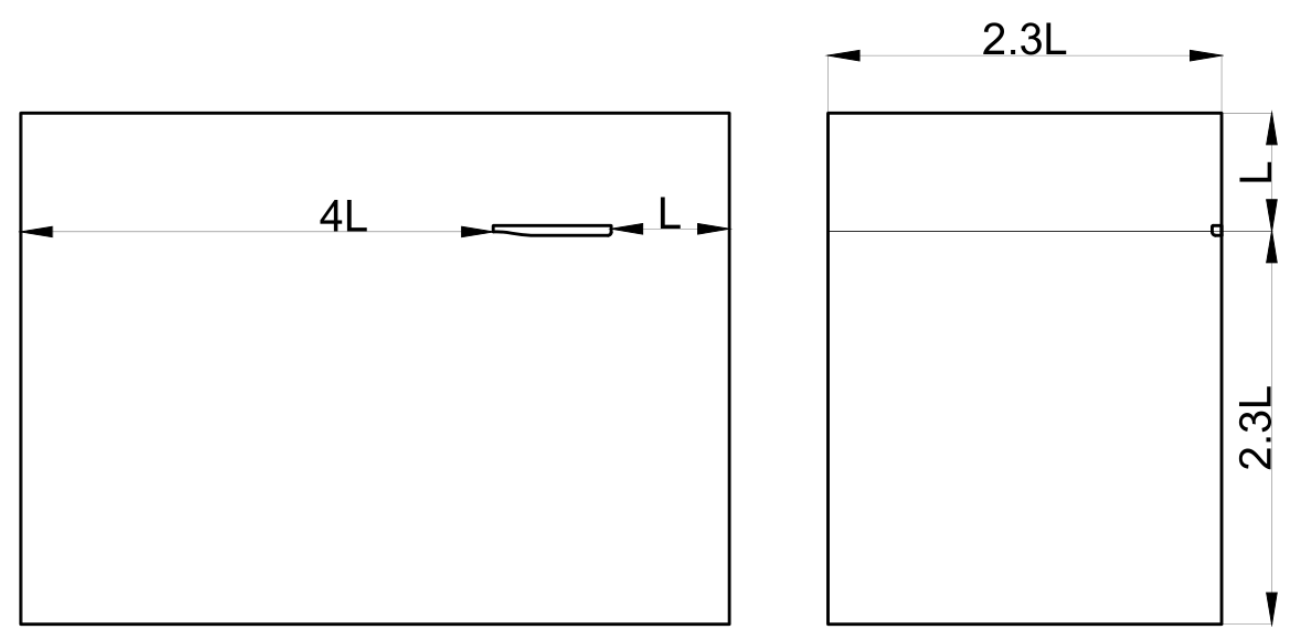

Figure 12 Computational domain dimensions (L: length between perpendiculars)

\subsubsection{Boundary conditions}

In order to obtain accurate and realistic results, it is important that the boundary conditions are set correctly. A general view of the computation domain with the RoPax model and the notations of selected boundary conditions are depicted in Figure 13. In order to reduce computational demand, a symmetry plane was applied at the centreline of the hull, meaning only half of the hull is presented in the analysis. Figure 13 describes that a velocity inlet boundary condition was set in the upstream direction. A pressure outlet boundary was modelled behind the ship as it prevents backflow from occurring and keeps static pressure constant at the outlet. The top and bottom boundaries were both set as velocity inlets. Two sides of the domain have a symmetry boundary condition. These stated boundary conditions were selected because they were reported to give the quickest solutions for similar work performed using the Star-CCM+ software (CD-Adapco, 2016). As clearly explained in Tezdogan et al. (2015), the employment of the velocity inlet boundary condition at the top and bottom prevents the fluid from sticking to the walls. It should be noted that the top, bottom and side boundaries could have been modelled as a slip-wall boundary condition.

It is worth noting that throughout all the simulations, in order to prevent wave reflection from the boundaries, the VOF wave damping capability of Star-CCM+ was adopted to the computational domain with a damping length equal to a ship length. This numerical damping model was used in downstream and transverse directions. For the theory background of the wave damping model, reference may be made to Choi and Yoon (2009). 


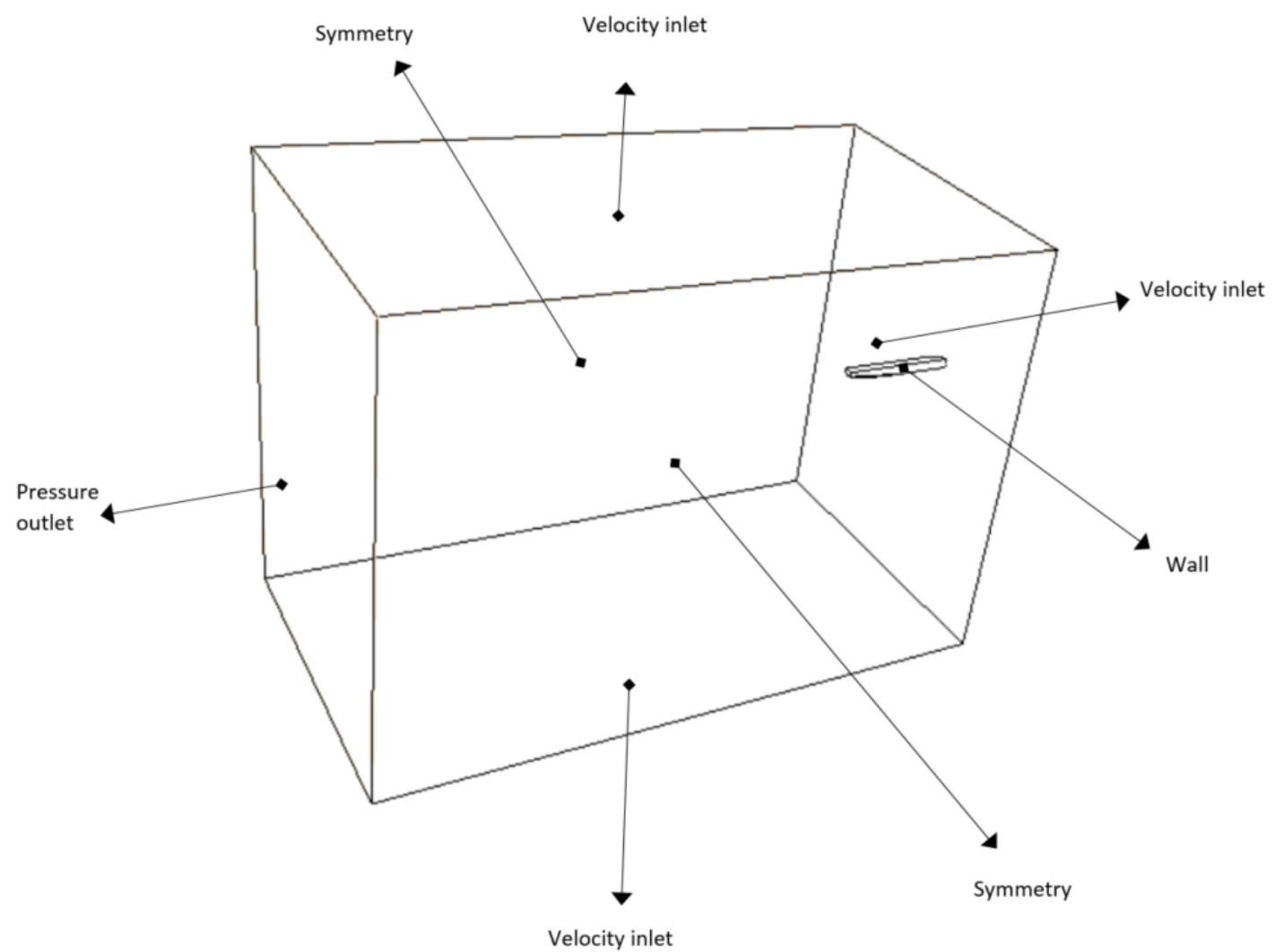

Figure 13 Domain boundary conditions

\subsubsection{Mesh generation}

By specifying the surface mesh, volume mesh and the optional prism layer mesh settings, Star-CCM+ offers an automatic meshing facility. This feature allows the user to enhance a finer mesh around areas where important flow features are expected to occur, by creating volumetric control areas. In this case, volumetric refinements were set up around the hull, skeg and the free surface as well as in the wake produced by the vessel. The mesh generation applied for resistance simulation resulted in a computational mesh of circa 4.75 million cells in total. Figure 14 shows a cross sectional view of the volume mesh generated inside the domain and Figure 15 displays the surface mesh on the hull with skegs. 


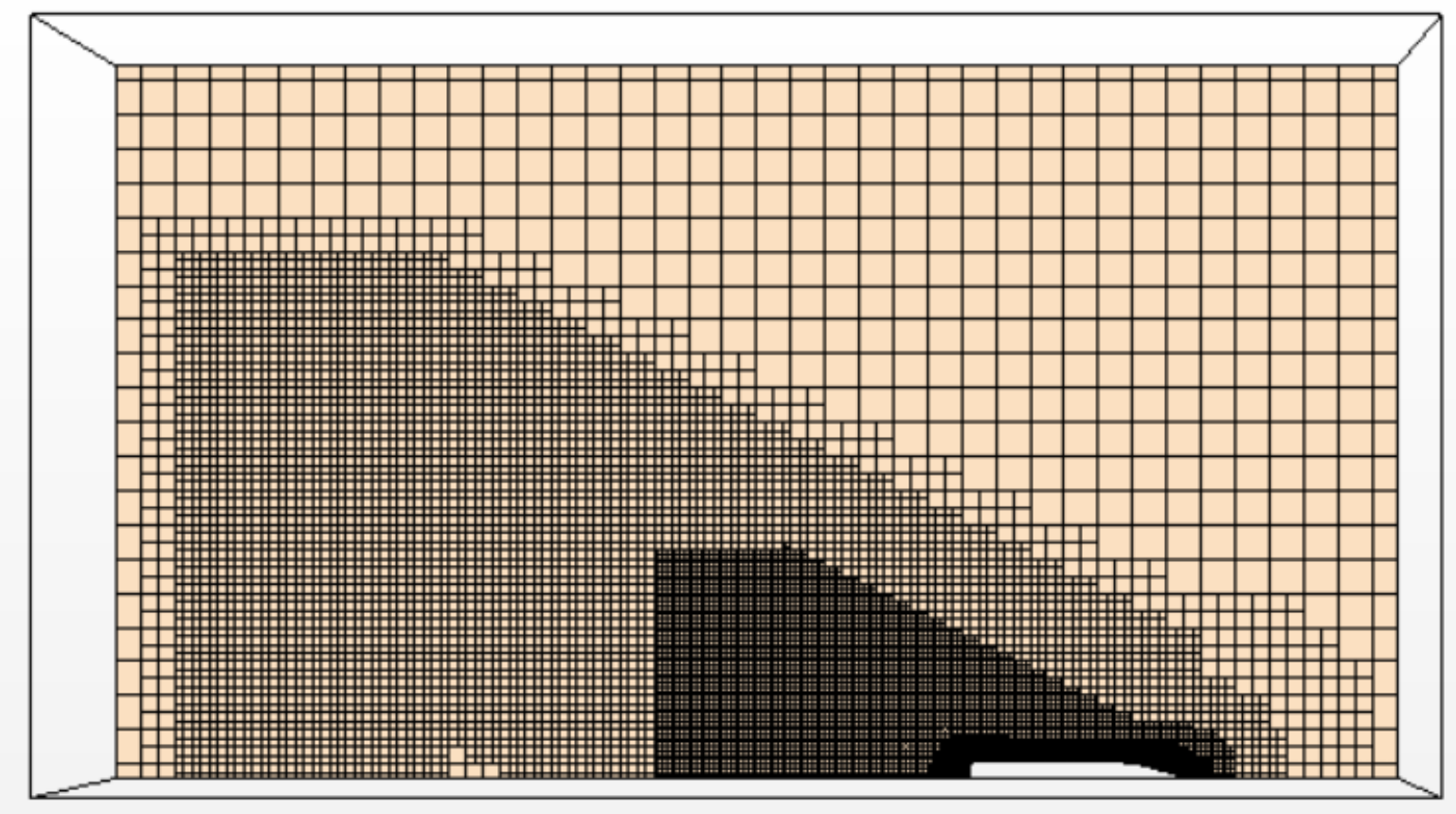

Figure 14 A cross section of the computational mesh around the vessel

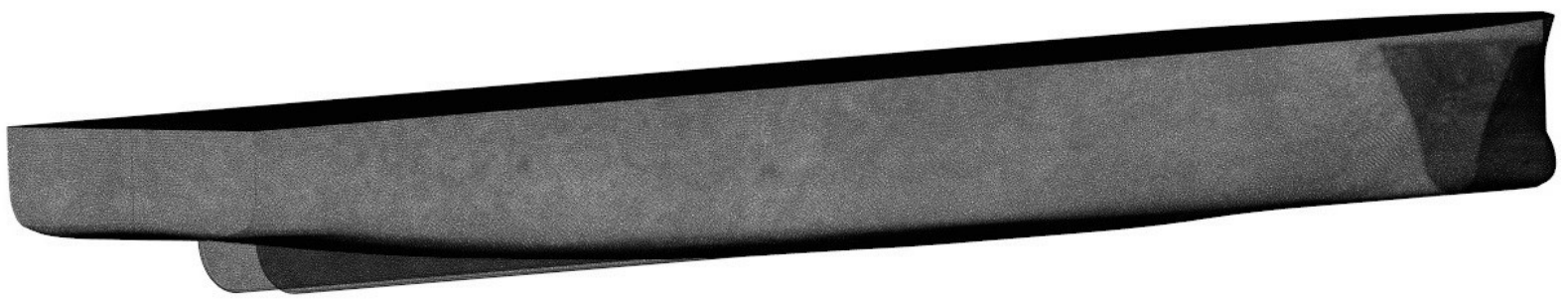

Figure 15 A view of the surface mesh on the ship hull with skegs

\section{Results and discussion}

The design of the RoPax ferry features nine decks, with a total of 306 cabins and a passenger capacity of 1400 divided over three accommodation decks. The total length of the vehicle lanes is $1950 \mathrm{~m}$ (lane meters), divided over three vehicle decks. There are three different cabin modules - single cabin, couples cabin and family cabin.

The following section will outline the results achieved during the research. This section is divided into six parts, each looking into different aspects of our results. Before proceeding to assess the obtained results, it is first necessary to undertake a proper verification study to assess the CFD model's uncertainty. A similar verification study was also performed by Tezdogan et al. (2016), in which the heave and pitch motions of a large tanker model were predicted in shallow water areas utilising Star$\mathrm{CCM}+$. 


\subsection{Verification study}

The CFD work's verification study was undertaken to estimate the discretisation errors due to gridsize and time-step resolutions for the resistance simulation at 24 knots. It is expected that the numerical uncertainties for the other cases are of the same order.

Xing and Stern (2010) state that the Richardson extrapolation (RE) method (1911) is the basis for existing quantitative numerical error/uncertainty estimates for time-step convergence and grid-spacing. With this method, the error is expanded in a power series, with integer powers of grid-spacing or timestep taken as a finite sum. Commonly, only the first term of the series will be retained, assuming that the solutions lie in the asymptotic range. This practice generates a so-called grid-triplet study. Roache's (1998) grid convergence index (GCI) is useful for estimating uncertainties arising from gridspacing and time-step errors. Roache's GCI is recommended for use by both the American Society of Mechanical Engineers (ASME) (Celik et al., 2008) and the American Institute of Aeronautics and Astronautics (AIAA) (Cosner et al., 2006).

For predicting iterative errors, the procedure derived by Roy and Blottner (2001) was employed. The results obtained from these calculations suggest that the iterative errors for both force coefficients are equal to almost zero.

Grid-spacing and time-step convergence studies were carried out following the GCI method described in Celik et al. (2008). The convergence studies were performed with triple solutions using systematically refined grid-spacing or time-steps. For example, the grid convergence study was conducted using three calculations in which the grid size was systematically coarsened in all directions whilst keeping all other input parameters (such as time-step) constant. The mesh convergence analysis was carried out with the smallest time-step, whereas the time-step convergence analysis was carried out with the finest grid size.

To assess the convergence condition, the convergence ratio $\left(\mathrm{R}_{\mathrm{k}}\right)$ is used, as given by:

$R_{k}=\frac{\varepsilon_{k 21}}{\varepsilon_{k 32}}$

where $\varepsilon_{\mathrm{k} 21}=\varphi_{\mathrm{k} 2}-\varphi_{\mathrm{k} 1}$ and $\varepsilon_{\mathrm{k} 32}=\varphi_{\mathrm{k} 3}-\varphi_{\mathrm{k} 2}$ are the differences between medium-fine and coarse-medium solutions, and $\varphi_{\mathrm{k} 1}, \varphi_{\mathrm{k} 2}$ and $\varphi_{\mathrm{k} 3}$ correspond to the solutions with fine, medium and coarse input parameters, respectively. The subscript $\mathrm{k}$ refers to the $\mathrm{k}^{\text {th }}$ input parameter (i.e. grid-size or time-step) (Stern et al., 2006).

Four typical convergence conditions may be seen: (i) monotonic convergence $\left(0<\mathrm{R}_{\mathrm{k}}<1\right)$, (ii) oscillatory convergence $\left(\mathrm{R}_{\mathrm{k}}<0 ;\left|\mathrm{R}_{\mathrm{k}}\right|<1\right)$, (iii) monotonic divergence ( $\left.\mathrm{Rk}>1\right)$, and (iv) oscillatory divergence $\left(\mathrm{R}_{\mathrm{k}}<0 ;\left|\mathrm{R}_{\mathrm{k}}\right|>1\right)$. For diverging conditions (iii) and (iv), neither error nor uncertainty can be assessed (Stern et al., 2006). For convergence conditions, the generalized RE method is applied to 
predict the error and order-of-accuracy $\left(p_{k}\right)$ for the selected $\mathrm{k}^{\text {th }}$ input parameter. For a constant refinement ratio $\left(r_{k}\right), p_{k}$ can be calculated by:

$$
p_{k}=\frac{\ln \left(\varepsilon_{k 32} / \varepsilon_{k 21}\right)}{\ln \left(r_{k}\right)}
$$

The extrapolated values can be calculated from Celik et al. (2008).

$$
\phi_{e x t}^{21}=\left(r_{k}^{p} \phi_{1}-\phi_{2}\right) /\left(r_{k}^{p}-1\right)
$$

The approximate relative error and extrapolated relative error can then be calculated using Equations 5 and 6, respectively (Celik et al., 2008):

$$
\begin{aligned}
& e_{a}^{21}=\left|\frac{\phi_{1}-\phi_{2}}{\phi_{1}}\right| \\
& e_{e x t}^{21}=\left|\frac{\phi_{e x t}^{12}-\phi_{1}}{\phi_{e x t}^{12}}\right|
\end{aligned}
$$

Finally, the fine-grid convergence index is predicted by:

$$
G C I_{\text {fine }}^{21}=\frac{1.25 e_{a}^{21}}{r_{k}^{p}-1}
$$

It should be borne in mind that Equations 2-7 are valid for a constant $r_{k}$ value. Reference can be made to Celik et al. (2008) for the formulae valid for a non-constant refinement ratio. The notation style of this reference was used in this study in order to enable the verification results to be presented clearly.

For both the mesh-spacing and time-step convergence studies, a constant refinement ratio of $\sqrt{2}$ was chosen in this study. It is of importance to mention that during the mesh convergence study, the surface mesh properties on the ship surface were kept constant to model the hull geometry accurately. Based on the mesh refinement ratio which was applied, the final mesh numbers for each mesh configuration are listed in Table 5. Similarly, the time-step convergence study was conducted with triple solutions using systematically lessened time-steps, starting from $\Delta \mathrm{t}=0.0075 \mathrm{~L} / \mathrm{U}$. 
Table 5. The final cell numbers for each mesh configuration as a result of the mesh convergence study

\begin{tabular}{|l|l|}
\hline Mesh Configuration & Total cell number \\
\hline Fine & $4,753,289$ \\
\hline Medium & $2,988,720$ \\
\hline Coarse & $1,740,213$ \\
\hline
\end{tabular}

The verification parameters of the resistance for the grid spacing and time-step convergence studies are presented in Table 6 .

Table 6. Grid and time-step convergence studies for ship hull resistance

\begin{tabular}{|l|l|l|}
\hline & Grid convergence & Time-step convergence \\
\hline & $\begin{array}{l}\text { Total hull resistance }\left(\mathrm{R}_{\mathrm{H}}\right) \\
\text { (with monotonic } \\
\text { convergence) }\end{array}$ & $\begin{array}{l}\text { Total hull resistance }\left(\mathrm{R}_{\mathrm{H}}\right) \\
\text { (with monotonic } \\
\text { convergence) }\end{array}$ \\
\hline $\mathrm{r}$ & $\sqrt{2}$ & $\sqrt{2}$ \\
\hline$\varphi_{1}$ & $1628.5 \mathrm{kN}$ & $1628.5 \mathrm{kN}$ \\
\hline$\varphi_{2}$ & $1563.8 \mathrm{kN}$ & $1549.4 \mathrm{kN}$ \\
\hline$\varphi_{3}$ & $1446.1 \mathrm{kN}$ & $1415.3 \mathrm{kN}$ \\
\hline $\mathrm{R}$ & 0.550 & 0.589 \\
\hline $\mathrm{p}$ & 1.727 & 1.523 \\
\hline$\varphi_{\mathrm{ext}}{ }^{21}$ & $1707.5 \mathrm{kN}$ & $1742.26 \mathrm{kN}$ \\
\hline $\mathrm{e}_{\mathrm{a}}{ }^{21}$ & $3.97 \%$ & $4.86 \%$ \\
\hline $\mathrm{e}_{\mathrm{ext}}{ }^{21}$ & $4.63 \%$ & $6.53 \%$ \\
\hline $\mathrm{GCI}_{\text {fine }}{ }^{21}$ & $6.06 \%$ & $8.73 \%$ \\
\hline
\end{tabular}

As can be seen from Table 6, the resistance results tend to decrease monotonically as the grid or timestep resolutions are systematically lessened. The levels of uncertainty were deemed to be sufficient for this study. The numerical uncertainties in the finest-grid solution for grid and time-step convergence tests are predicted as $6.06 \%$ and $8.73 \%$, respectively. It can be interpreted that a smaller time-step resolution should be applied to obtain a smaller uncertainty level.

\subsection{Ship comparison and internal arrangement optimisation analysis}

This section will compare the ship in question with similar ships which currently are in service, with approximately the same size and capacity. The capacity will be compared in terms of passenger capacity and lane meters. The block coefficient is not included in the comparison, because this parameter tends to be difficult to obtain. As each ship is designed for its own purposes and exact specifications tend to be confidential, a direct comparison is not possible. The comparison is done in order to validate that the design carried out in this study is within reasonable limits. Table 7 shows some of the main particulars of three similar RoPax ferries. The bottom row of the table represents the difference from the average values of the three comparison ships. 
Table 7 Ship main design parameter comparison. Sources: MS Mega Express Four - Corsica Ferries, MS Calais Seaways - DFDS Seaways and MS Stena Saga - Stena Line.

\begin{tabular}{|l|c|c|c|c|c|}
\hline Name & $\mathbf{L}_{\mathbf{O A}}(\mathbf{m})$ & $\mathbf{B}(\mathbf{m})$ & $\mathbf{T}(\mathbf{m})$ & Passenger capacity & Lane meters (m) \\
\hline MS Mega Express Four & 173.50 & 24.00 & 6.41 & 1400 & 1850 \\
\hline MS Calais Seaways & 165.00 & 26.00 & 6.30 & 1100 & 1784 \\
\hline MS Stena Saga & 165.50 & 28.40 & 6.80 & 2000 & 1800 \\
\hline This study's ferry & 150.00 & 24.00 & 5.50 & 1400 & 1950 \\
\hline Relative difference (\%) & -10.71 & -8.16 & -15.43 & -6.67 & 7.66 \\
\hline
\end{tabular}

The comparison shows that the vessel has successfully been designed to be smaller and more compact in terms of length, breadth and draft. The comparison also shows that the internal arrangement of the vessel has been designed with a high capacity in terms of lane meters, but the capacity of passengers is, however, lower than the average of the ships in the comparison.

\subsection{CFD results}

The following sub-section will outline the CFD results achieved.

\subsubsection{Ship resistance}

The resistance characteristics of the ferry in calm water $\left(\mathrm{R}_{\mathrm{H}}\right)$ were estimated at various speeds using CFD. The resistance values were calculated by taking the average of the drag values over the last 30 seconds of a time history record. These figures are obtained under an idealised trial condition which refers to a clean hull and which neglects waves and winds. However in normal service conditions the power required to propel the vessel in a certain speed is higher than the one predicted in the trial conditions. This increase is commonly referred to as 'sea margin' or 'powering margin'. ITTC (2005) defines the powering margin as "the margin which should be added to the estimation of the speedpower relationship for a newly built ship in ideal weather conditions to allow for the operation of the ship in realistic conditions". Powering margins take into calculation environmental effects (such as wind and waves) and the effects of ageing and fouling as well as hull roughness. As stated in ITTC (2005) a typical value for a powering margin can be taken to be $15-25 \%$ of the total hull resistance in calm water.

In this study the powering margin was taken to be $22 \%$ as per the ITTC's suggestion. However, in our CFD simulations the hull was modelled without bow thrusters and propellers, so an additional factor must be added to account for their resistance. As suggested by Huber (2016) a margin of $2 \%$ per bow thruster and propeller was added to the powering margin which increased the powering margin from $22 \%$ to $26 \%$. This means that the total hull resistance values obtained from the CFD simulations were increased by $26 \%$ to account for the real operational and environmental conditions.

The resistance characteristics of the ferry obtained under idealised trial conditions $\left(R_{H}\right)$ and real operational conditions $\left(\mathrm{R}_{\mathrm{T}}\right)$ are given in Table 8. Figure 16 shows the total ship resistance under operational conditions $\left(\mathrm{R}_{\mathrm{T}}\right)$ over varying ship speeds. As stated earlier, the CFD analyses were 
completed for $15,18,20,22$ and 24 knots, so the values between 15 knots and 0 knots were simply extrapolated.

Table 8 The resistance characteristics of the ferry in question obtained for trial and sea conditions for different speeds

\begin{tabular}{|l|l|l|}
\hline $\begin{array}{l}\text { Ship } \\
\text { speed } \\
(\mathbf{k n})\end{array}$ & $\begin{array}{l}\text { Ship resistance in calm } \\
\text { water (obtained from } \\
\text { CFD) }\left(\mathbf{R}_{\mathbf{H}}\right)(\mathbf{k N})\end{array}$ & $\begin{array}{l}\text { Total ship resistance in } \\
\text { operational sea } \\
\text { conditions }\left(\mathbf{R}_{\mathbf{T}}\right)(\mathbf{k N})\end{array}$ \\
\hline 15 & 472.74 & 595.665 \\
\hline 18 & 708.15 & 892.269 \\
\hline 20 & 903.05 & 1137.843 \\
\hline 22 & 1200.35 & 1512.441 \\
\hline 24 & 1628.5 & 2051.910 \\
\hline
\end{tabular}

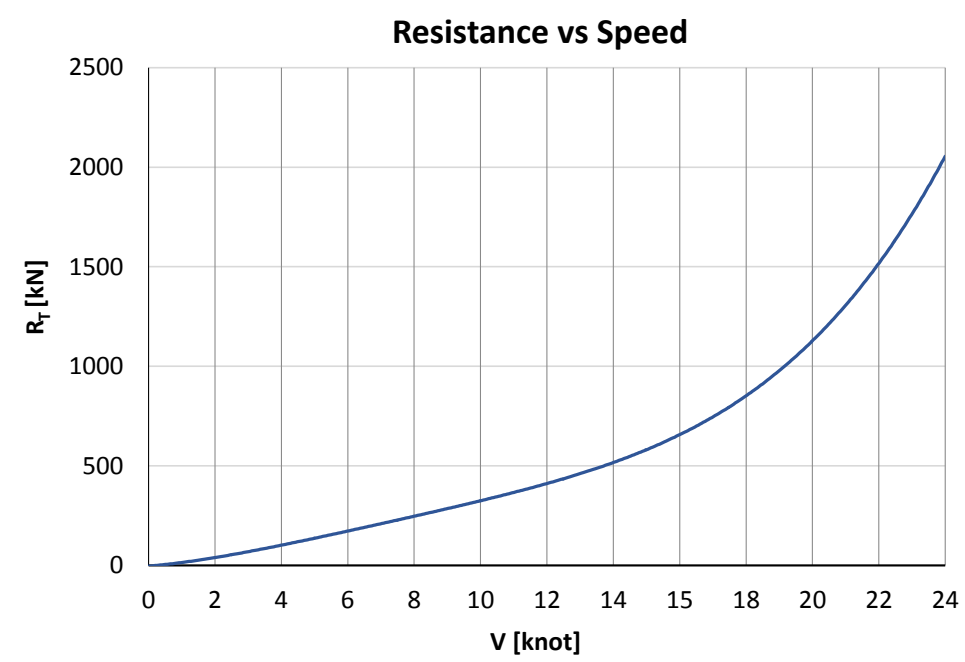

Figure 16 The total resistance $\left(\mathrm{R}_{\mathrm{T}}\right)$ values over a range of ship forward speeds

\subsubsection{Pressure distribution}

Visualising the pressure distribution around the ship's hull is an important tool for naval architects to identify the areas where high pressure and therefore high stress is expected to occur. Such areas are often prone to cracking or collapsing and therefore must be supported with structural members. As can be seen from the pressure distribution around the ship's hull in Figures 17 and 18, the bow and skegs experience the highest pressure values, though these pressure values are smaller than the yield strength of marine hull steel. 


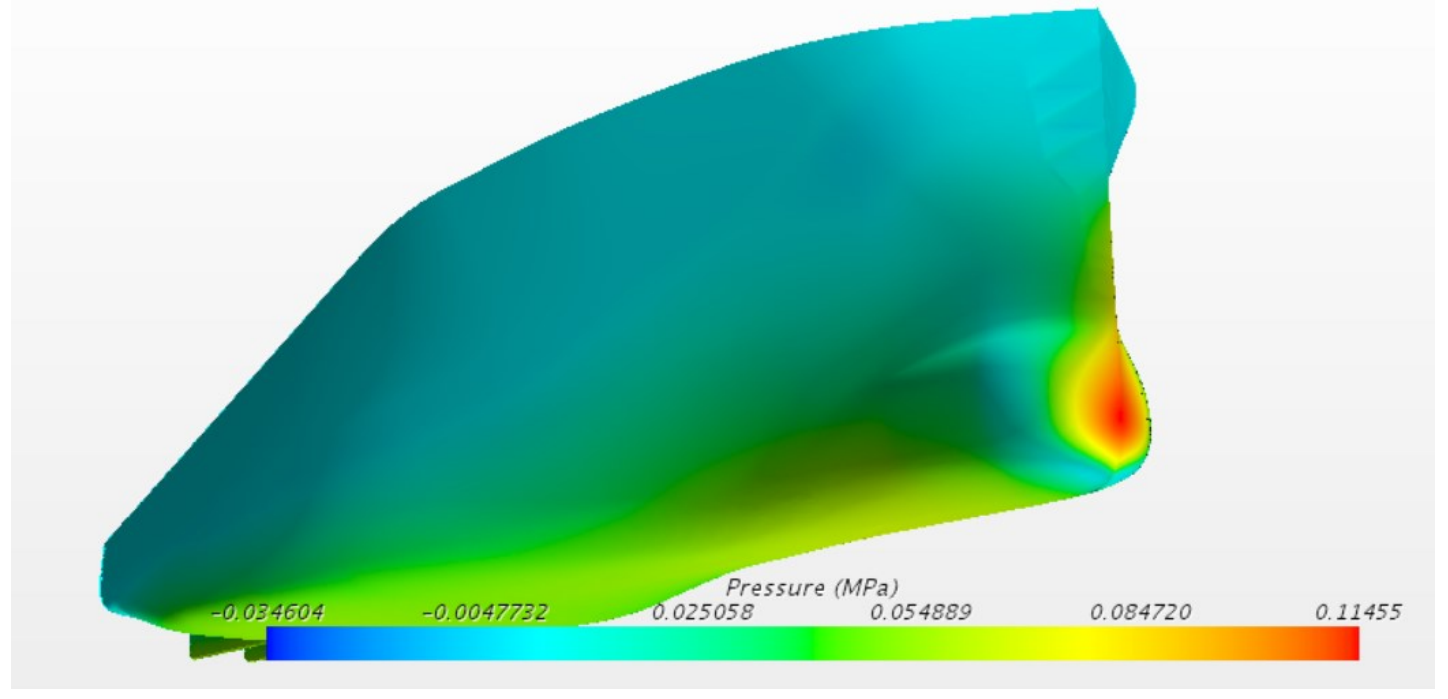

Figure 17 Pressure distribution on the ship's hull at 24 knots (a view from the bow)

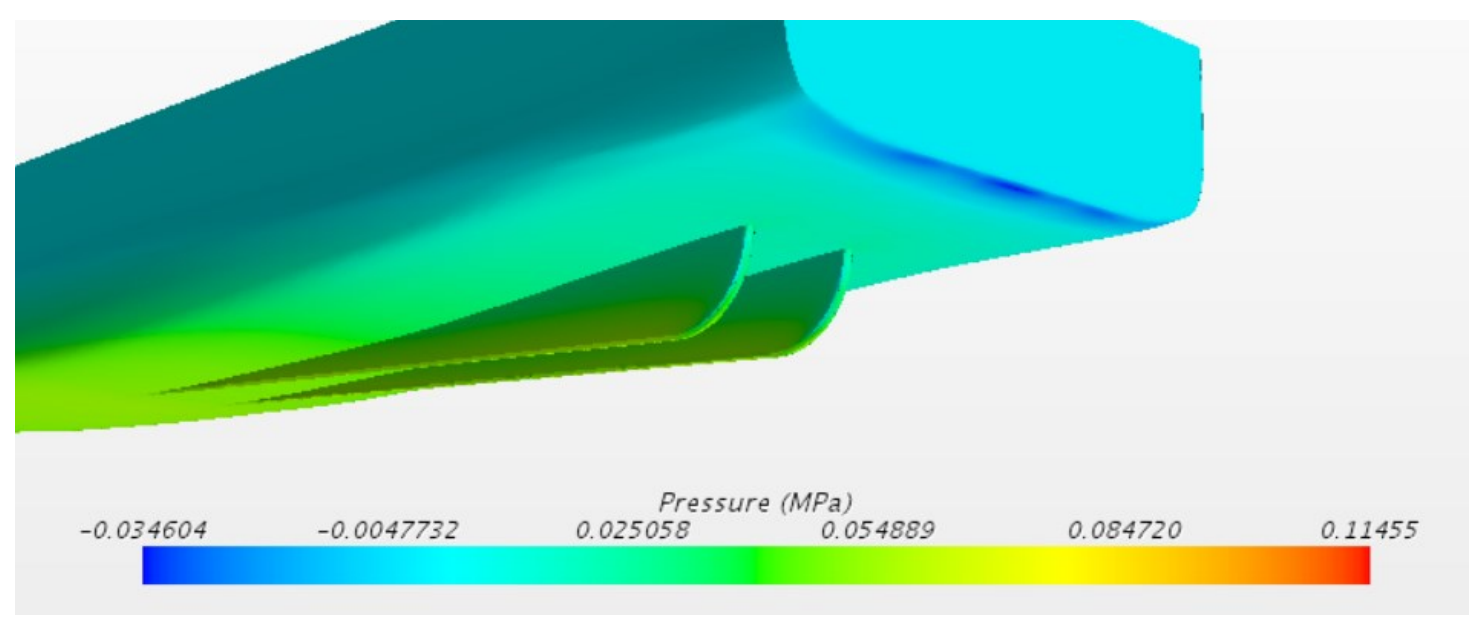

Figure 18 Pressure distribution on the vessel surface at 24 knots (a view from the stern)

\subsubsection{Wave pattern}

As a ship sails through the water, it generates waves behind it on the free surface. This section will show and compare the wave patterns obtained from the RANS solver at different forward speeds.

Figures 19, 20 and 21 show the global water pattern around the RoPax ferry after the simulations have completed their runs at 15, 20 and 24 knots, respectively. The resultant wavelength and wave height tend to increase as the ship speed increases. The generated Kelvin Wakes behind the vessel are clearly visible in these figures due to a fine mesh generated in these areas. It is not this paper's aim to further investigate the theory of the Kelvin Wake, though it is necessary to understand the basics of it. The Kelvin Wake consists of two main components - one divergent wave and one transverse wave. As Figure 22 shows, the divergent waves are created along the wake line at an angle of $\approx 19.5^{\circ}$, and the "feathery arms" that create the visual appearance of the waves have an angle of $\approx 55^{\circ}$ relative to the centreline of the ship. The transverse waves that are formed between the wake lines have a circular shape with a diameter equal to the distance from the ship (Rozman, 2009). 


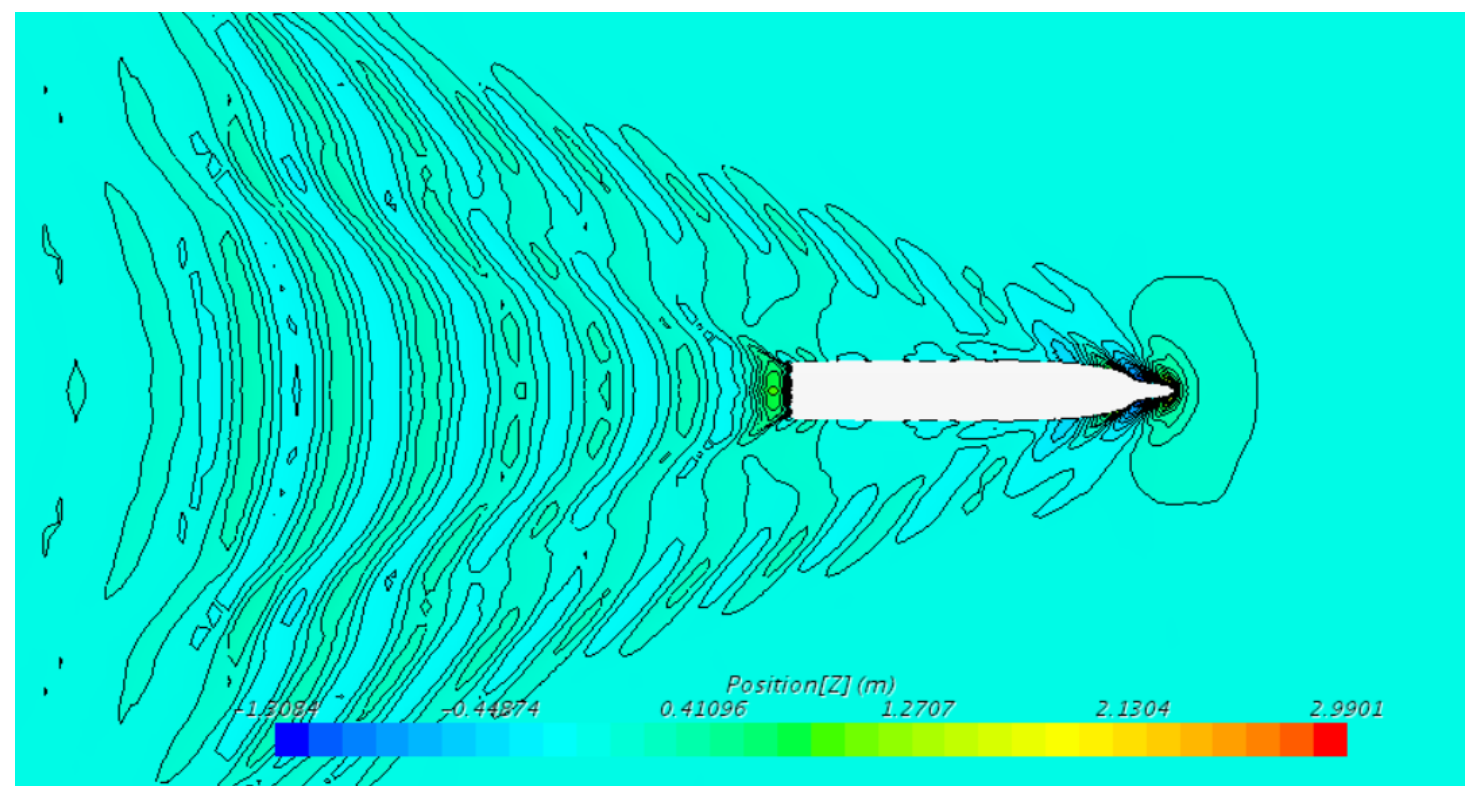

Figure 19 Calculated wave pattern behind the vessel at 15 knots

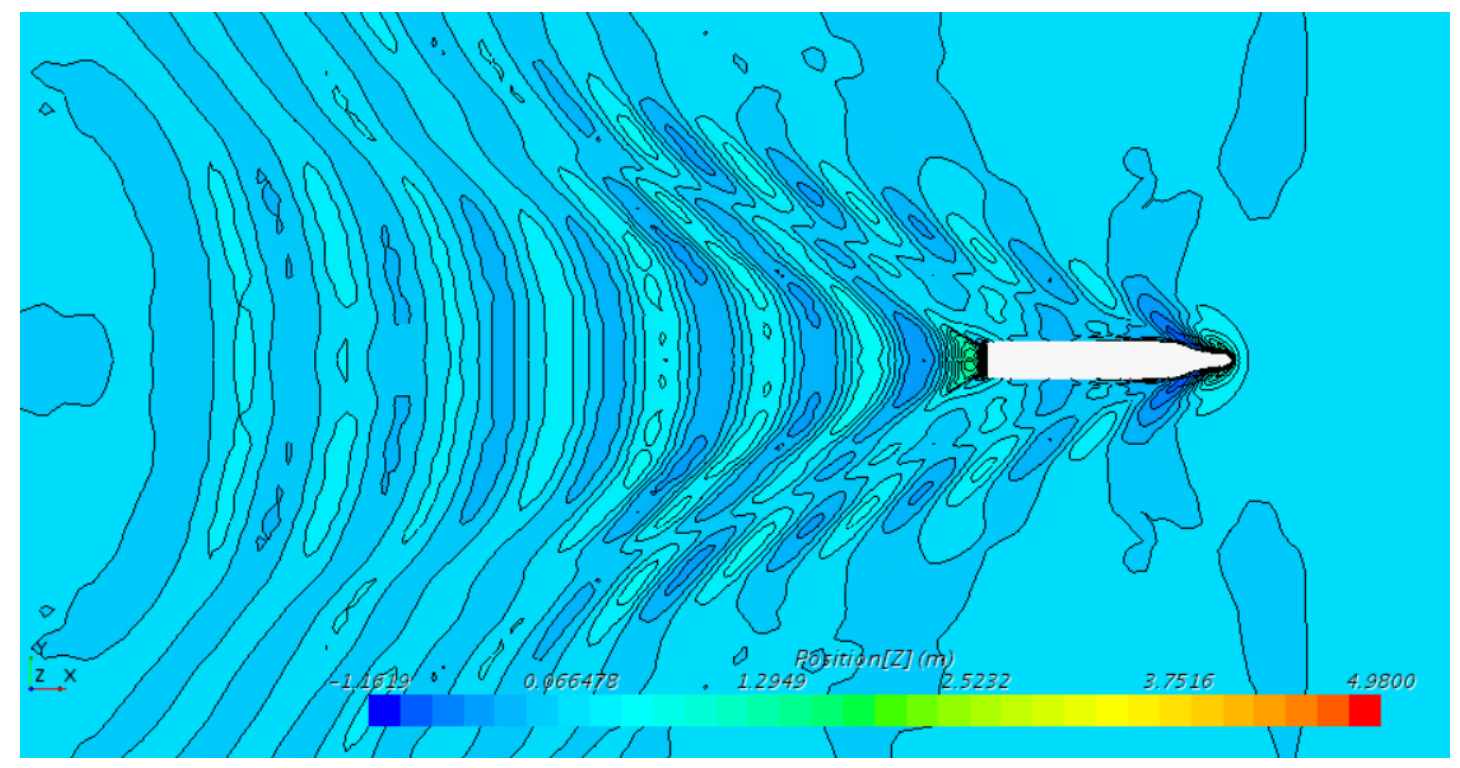

Figure 20 Calculated wave pattern behind the vessel at 20 knots

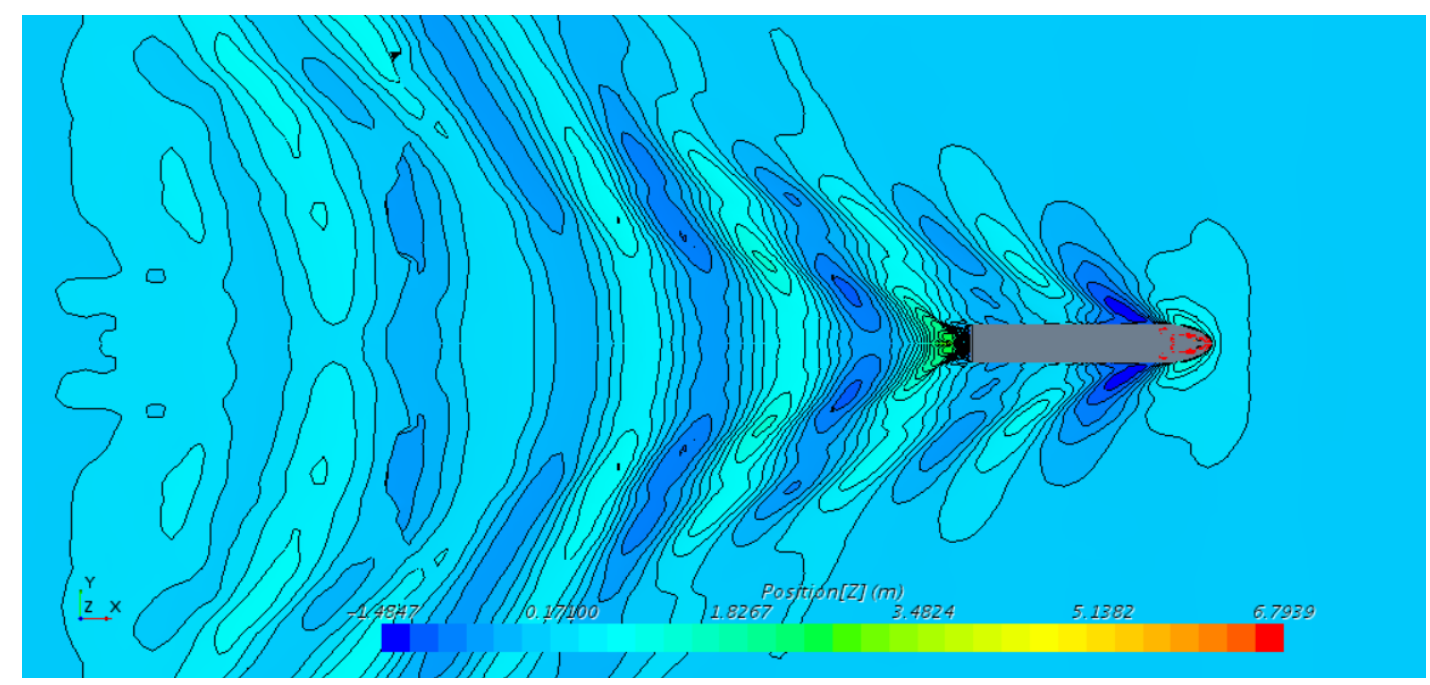

Figure 21 Calculated wave pattern behind the vessel at 24 knots 


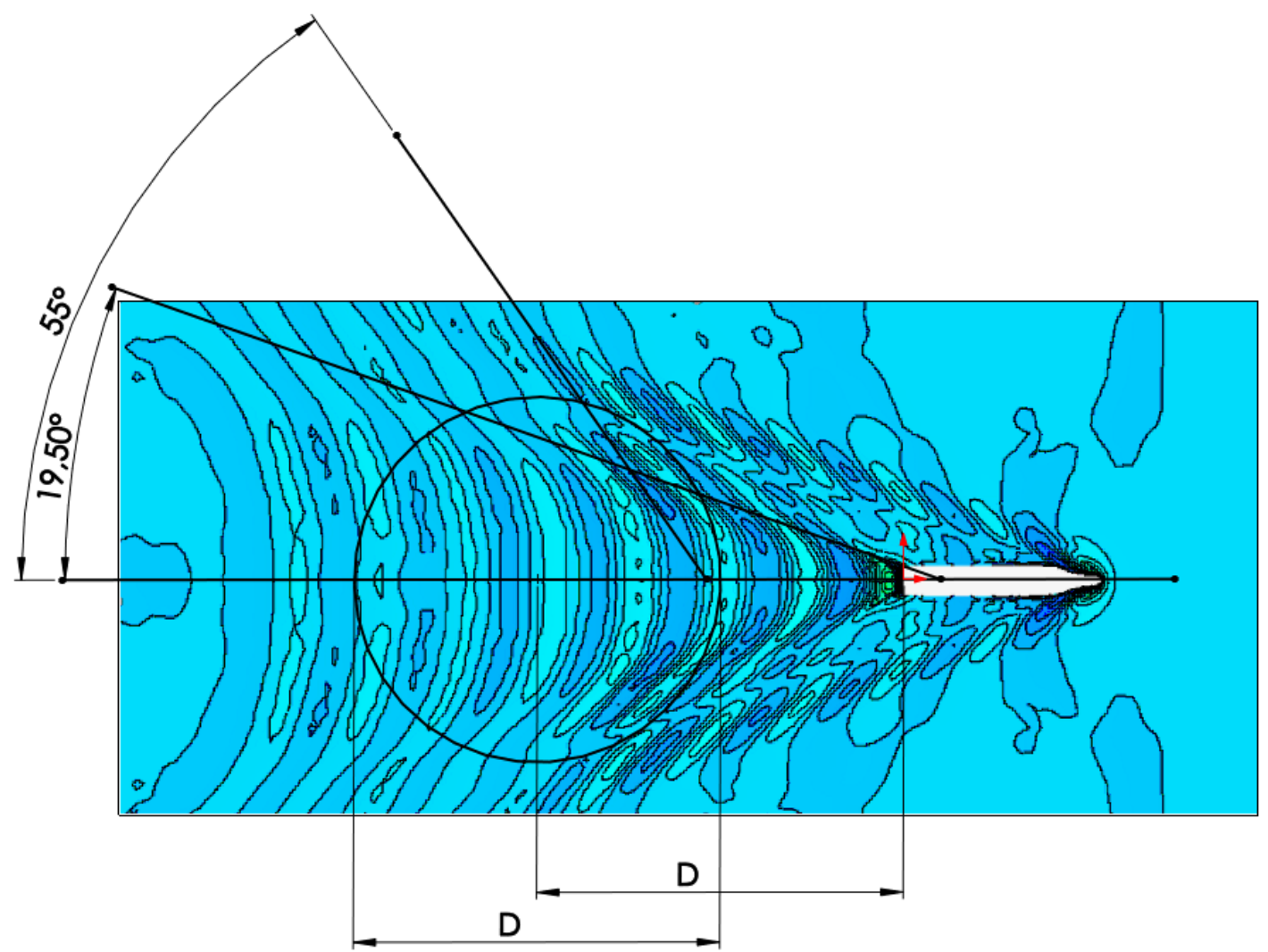

Figure 22 Illustration of the Kelvin Wake generated by the ship

\subsubsection{Trim and sinkage}

The ship was, as previously mentioned, free to sink and trim during all the simulations. This allows the model to translate along the z-axis, and rotate about the y-axis freely. Table 9 lists the trim and sinkage values obtained from CFD measured at the ship's centre of gravity $(\mathrm{CoG})$ for different speeds. A negative sinkage value indicates the vessel sits larger in the water. As can be seen from the table, the sinkage values increase with increasing speed, as expected.

Table 9 Comparison of trim and sinkage values measured at the ship's CoG in CFD

\begin{tabular}{|l|l|l|}
\hline Ship speed (kn) & Trim $^{\left({ }^{\circ}\right)}$ & Sinkage (m) \\
\hline 15 & 0.059 & -0.141 \\
\hline 18 & 0.077 & -0.214 \\
\hline 20 & 0.083 & -0.282 \\
\hline 22 & 0.059 & -0.359 \\
\hline 24 & 0.014 & -0.427 \\
\hline
\end{tabular}

\subsubsection{Free surface}

The free surface is not fixed; it is dependent on the specifications of the flat wave, with the VOF model making calculations for both the water and air phases. The grid is simply refined in order to enable the variations in volume fraction to be more accurately captured. In this study, a second-order convection scheme was used throughout all simulations in order to accurately capture sharp interfaces between the phases. 


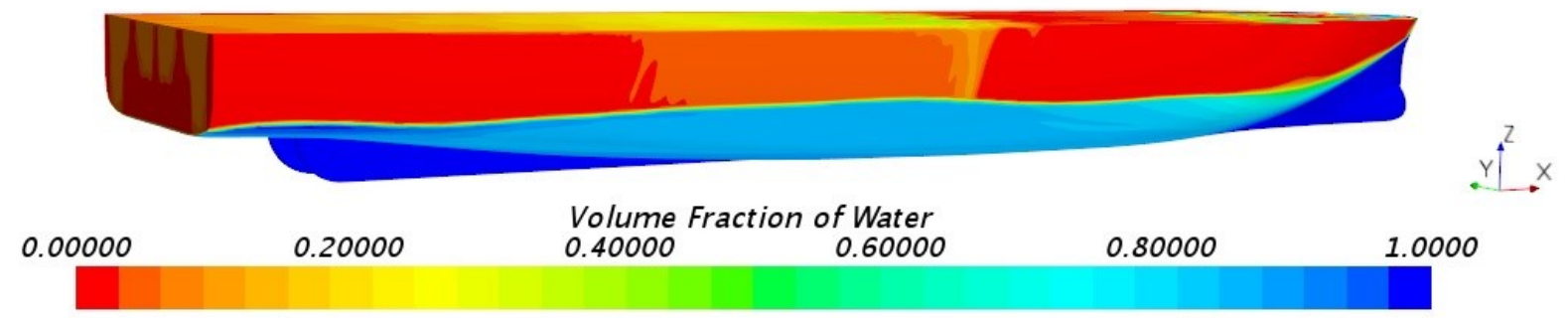

Figure 23 Free surface representation on the vessel surface (at 24 kn)

Figure 23 displays how the free surface was represented in Star-CCM+ by demonstrating the volume fraction of the water profile on the vessel surface. In the figure, for example, a value of 0.5 for the volume fraction of water means that a computational cell is filled with $50 \%$ water and $50 \%$ air.

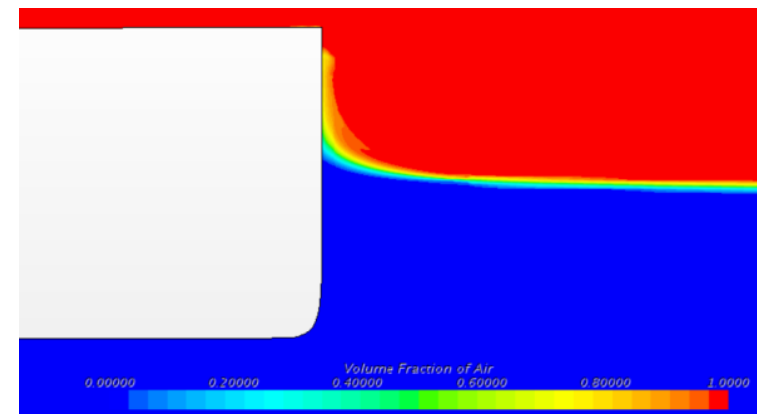

Figure 24 Free water at the bow (at 24 kn)

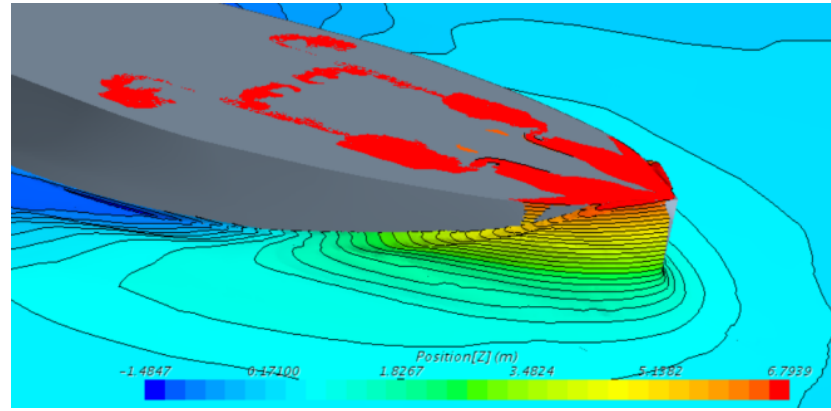

Figure 25 Wave run-up around the bow (at $24 \mathrm{kn}$ )

Having a closer look at the free surface around the bow as shown in Figures 24 and 25, it is evident to see the small amount of green water on the deck. This is mainly due to the fact that the ship geometry has a small flare angle which causes a green water on deck incident at high speeds. This figure implies that the bow area should be better designed to minimise, if not prevent, green water loads.

\subsection{Power requirements}

Since the total hull resistance of the ferry has been obtained in sub-section 4.3.1, the brake power of the main engine to propel the ship in a specific constant speed taking into account efficiency parameters will be calculated in this sub-section.

The procedure from MAN (2011) is employed to obtain the power parameters of the ship in question. Before giving our findings, it would be fitting to give the formulae used in the power calculations, as taken from Chapter 2 of the paper given by MAN (2011):

Effective power: $P_{E}=R_{H} x V$

Thrust power: $P_{T}=P_{E} / \eta_{H}$ 
Delivered power: $P_{D}=P_{T} / \eta_{B}$

Brake power: $P_{B}=P_{D} / \eta_{S}$

in which $V$ denotes ship speed and $\eta_{\mathrm{H}}, \eta_{\mathrm{B}}$ and $\eta_{\mathrm{S}}$ refer to hull efficiency, propeller efficiency and shaft efficiency, respectively. It is of importance to recall that the propeller efficiency working behind the ship is calculated as the product of open water propeller efficiency $\eta_{0}$ and the relative rotative efficiency $\eta_{R}$.

Efficiencies are commonly calculated using empirical formulation or data provided by manufacturers. Naval architecture text book such as 'Principles of Naval Architecture' series published by the Society of Naval Architects and Marine Engineers (SNAME) (Lewis, 1988) are also among the most cited references to find approximated values for efficiencies.

In order to calculate the brake power of the main engine for the ferry, the open water propeller efficiency $\left(\eta_{\mathrm{O}}\right)$ was taken to be 0.7 as provided by the propeller manufacturer (Huber, 2016). The other efficiencies were taken to be as follow: $\eta_{\mathrm{R}}=0.985, \eta_{\mathrm{S}}=0.988$ and $\eta_{\mathrm{H}}=0.922$ (MAN, 2011 and Lewis, 1988).

Using the expressions given in Equation 8 with the efficiencies provided above, the brake powers of the main engine for this work's vessel are calculated for various ship speeds, as graphed in Figure 26.

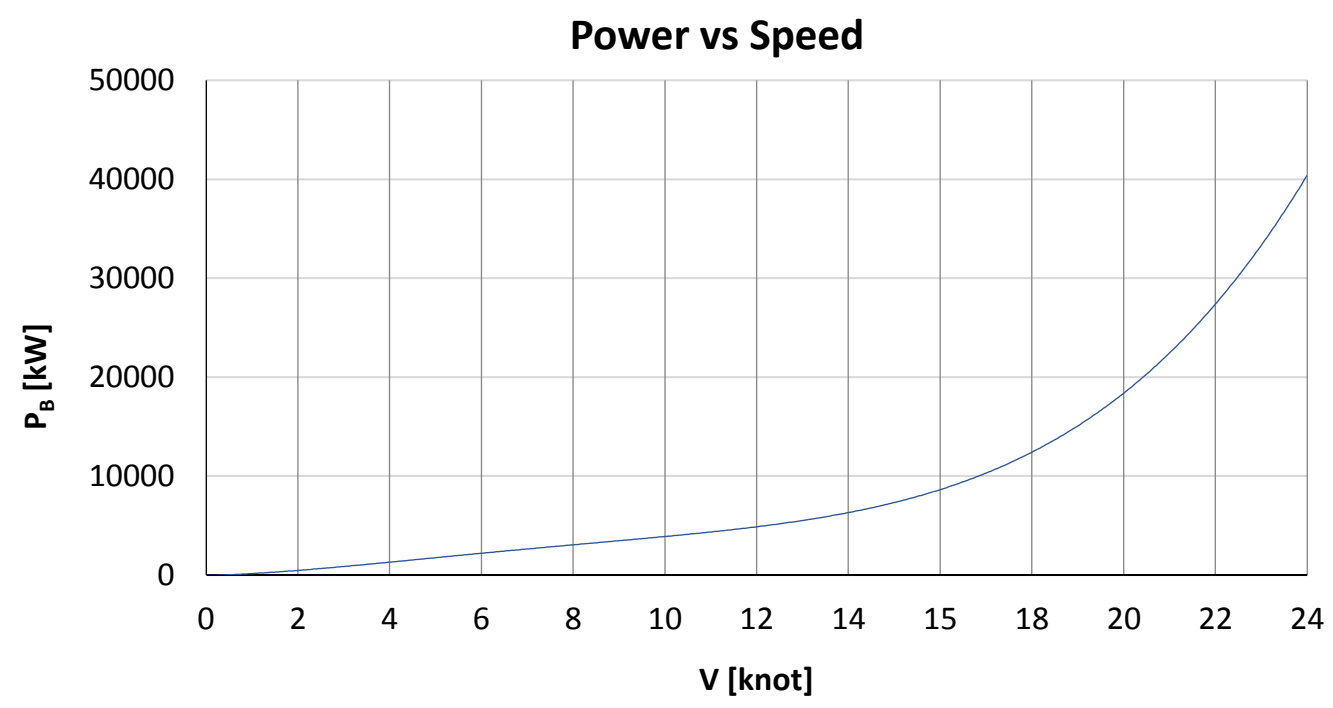

Figure 26 The brake power of the main engine installed in the ferry against different ship speeds

\subsection{Power plant investigation}

The power plant suggestions are made using the power requirements of the vessel as calculated in Section 4.4. Three different power plant configurations were investigated in this study, each of which 
will be outlined in the following sub-sections. Due to a sharp increase in the brake power of the vessel after 20 knots, the power plan arrangements will be made to meet a maximum speed of circa 20 knots.

\subsubsection{Power plant configuration 1: Hybrid diesel}

This configuration is based on the derivation of hybrid propulsion configurations in sub-section 2.4. As the engine room of the ferry was designed with a low roof height, the engines must be short in height to fit in the room. The straight two-stroke engines are known to be quite tall, so a four-stroke Vengine was selected for this reason.

For this purpose, the GE 16V250 diesel engine is suitable, which has a maximum continuous rating (MCR) of $4650 \mathrm{~kW}$ (General Electric Marine, 2013). This engine is currently the only engine that is able to fulfil the IMO Tier III NOx criteria without the usage of external equipment to clean the exhaust gas. The proposed power plant consists of four of the mentioned engines, resulting in a total MCR power output of $18600 \mathrm{~kW}$. It is predicted that the ship needs $800 \mathrm{~kW}$ for on-board usage, and for charging the batteries, which leaves $17800 \mathrm{~kW}$ to the propulsion plant. When taking the efficiency components shown in Figure 4 into account, the total power delivered to the propellers at MCR rises to $16180 \mathrm{~kW}$, which corresponds to a ship speed of 19.5 knots according to Figure 26.

It is assumed that the ferry requires $500 \mathrm{~kW}$ per hour for on-board usage when it is docked in the port for unloading and loading passengers and vehicles. Based on our prior experience, 1.5 hours for the loading and unloading process is sufficient for our ferry. It is also assumed that the vessel uses 1000 $\mathrm{kWh}$ when entering, and $1000 \mathrm{kWh}$ when exiting, the port. Given the fact that batteries exhibit longer lifespans when operated from an almost fully charged, rather than fully charged state, it is proposed that a battery pack of $4000 \mathrm{kWh}$ is enough for the ferry to be able to enter the port, unload, load and exit the port running solely on electricity.

\subsubsection{Power plant configuration 2: Hybrid LNG turbine}

This configuration is based on the same concept as above. The only difference is that the diesel engines are replaced with LNG fuelled turbines. Two of the Siemens SGT-300 turbines are selected, which have a MCR power output of $9200 \mathrm{~kW}$ each, giving a total power output of $18400 \mathrm{~kW}$ (Igoe et al., 2011).

As the purpose of this paper is to investigate green power plant options, we used a combined cycle steam and gas (COGAS) design with the turbine. Adding a steam cycle will boost the power output anywhere between $25 \%$ and $50 \%$ compared to the gas turbine only depending on the complexity of the steam cycle, the steam temperatures and pressures. Due to space constraints and safety on board a ship, it is common to use lower steam temperatures and pressures and simpler, less efficient steam turbine designs. In this configuration, we added a Heat Recovery Steam Generator (HRSG) along with a steam turbine to the plant unit as the second cycle. The function of the HRSG is to use the hot 
exhaust from the gas turbine to boil fluid into steam, which drives the steam turbine. Siemens' combined cycle test results suggest that for our case the extra cycle increases the power output by around $30 \%$, without increasing the fuel consumption (Welch, 2016). The extra cycle therefore increases the total MCR power output to $(18400 \mathrm{~kW} x 1.3=) 23920 \mathrm{~kW}$ which corresponds to a speed of 21.3 knots (Figure 26).

It is worth mentioning that the same battery pack as described in the last paragraph of sub-section 4.5.1 was proposed for this configuration as well.

\subsubsection{Power plant configuration 3: Conventional propulsion configuration}

The third power plant investigated in this study was a reference configuration that is commonly installed in RoPax ferries, as described in sub-section 2.2. In order obtain calculations that are representative for RoPax ferries in general, there will not be selected any specific engine for this configuration, but general values in terms of BSFC and emissions will be used for the later emission calculations.

The MCR value used for this configuration was set to be similar to the former suggestions, $18400 \mathrm{~kW}$. As this configuration does not have a battery pack, much of the produced power goes to the propellers rather than charging batteries. This results in a slightly higher forward speed of 19.7 knots (according to Figure 26). Additional auxiliary/port generators are required, in order to produce electricity for onboard usage when the ship is docked at the port.

It is worth emphasising that the cargo capacity in terms of lane meters would decrease when using this configuration. The reason for this is the mechanical connection (shaft) going from the main engines to the propellers, which requires a lot of space and consequently interferes with the lower car deck.

\subsection{Emission calculations}

This sub-section will outline the fundamental emission calculations pertaining to the vessel in question. The emissions were predicted for the pollutants described in sub-section 2.5 for each power plant configuration discussed in the previous sub-section.

The calculations were performed based on a scenario where the ferry is in service on a 300 nautical mile route, for 340 days over a year. The sailing speeds for all the three configurations were specified in sub-section 4.5. It is assumed in the calculations that the ferry spends 1.5 hours in the port between arrival and departure for unloading/loading. All details required for the emission calculations are given in the appendix.

The GHG emissions were calculated for each power plant configuration by using the formulae outlined in the reports by IMO (2015) and Kristiansen (2012). The input data which enabled us to perform the calculations was found in GE Marine's related report (2013). 
The first step to predict the GHG emissions from a ship is to calculate the fuel consumption of the vessel for a given route. Fuel consumption is calculated based on the BSFC value for the ship's main engine(s). Each engine has its own BSFC, which represents the mass of fuel consumed per power unit produced $\left(\left[\frac{g_{f u e l}}{k W h}\right]\right)$. In this study, the BSFC values were obtained from the engine manufacturers. The fuel consumption for a specific route is calculated by multiplying the BSFC value by the power output and the number of hours the engine is operating at this power level. In our case, the engine power, the number of running hours for an engine and the service speeds are taken for each plant configuration from the results presented in the previous sub-section.

$\mathrm{NO}_{\mathrm{x}}$ emissions were calculated in the same way as fuel consumption, as each engine has a specific emission rate of $\mathrm{NO}_{\mathrm{x}}$ per $\mathrm{kWh}$ produced. These values were also obtained from the engine manufacturers.

Similar to $\mathrm{NO}_{\mathrm{x}}$ emissions, the $\mathrm{CH}_{4}$ emissions are calculated as a specific rate of $\mathrm{CH}_{4}$ emissions per $\mathrm{kWh}$ produced. These values are dependent on the engine type, and were obtained from previous work by Welch and Kavli (2013).

$\mathrm{SO}_{\mathrm{x}}$ emissions are proportional with the fuel consumption and the content of sulfur in the fuel. The $\mathrm{SO}_{\mathrm{x}}$ emissions can be translated into a specific emission rate per tonne of fuel consumed as follows (Kristiansen, 2012):

$$
k g S O_{x} \text { emissions per tonne fuel oil consumed }=21 * S \quad\left[\frac{k g_{\text {sulphur }}}{\text { tonne }_{\text {fuel }}}\right]
$$

where $S$ is the percentage of sulfur in the fuel.

PM was calculated as a specific emission rate per power unit produced, as follows (Kristiansen, 2012):

$P M$ emissions in $\frac{g}{k W h}=0.26+0.081 * S+0.103 * S^{2} \quad\left[\frac{g_{P M}}{k W h}\right]$

The percentage of sulfur was taken to be $0.1 \%$ in the calculations, according to the MARPOL Annex VI criteria (IMO, 2014), as shown in Figure 7. As LNG does not contain sulfur, the configuration that utilises $\mathrm{LNG}$ as fuel has zero $\mathrm{SO}_{\mathrm{x}}$ and $\mathrm{PM}$ emissions.

Table 10 lists the calculated annual emissions based on the scenario and methods described above.

Table 10 Summary of the fuel consumption and emission calculations for each power plant configuration

\begin{tabular}{|l|l|l|l|}
\hline Configuration & $\begin{array}{l}\text { Hybrid } \\
\text { Diesel }\end{array}$ & $\begin{array}{l}\text { Hybrid LNG } \\
\text { turbine }\end{array}$ & $\begin{array}{l}\text { Reference } \\
\text { power plant }\end{array}$ \\
\hline Annual fuel consumption (tonnes) & 17512.62 & 19438.54 & 18267.42 \\
\hline Annual $\mathrm{CO}_{2}$ emissions (tonnes) & 56145.45 & 53455.98 & 58565.33 \\
\hline Annual $\mathrm{NO}_{\mathrm{x}}$ emissions (tonnes) & 204.31 & 45.82 & 1115.07 \\
\hline Annual $\mathrm{SO}_{\mathrm{x}}$ emissions (tonnes) & 36.76 & 0 & 38.52 \\
\hline Annual $\mathrm{PM}$ emissions (tonnes) & 26.18 & 0 & 56.56 \\
\hline Annual $\mathrm{CH}_{4}$ emissions (tonnes) & 1167.51 & 11.45 & 1184.14 \\
\hline
\end{tabular}


Table 10 shows that the hybrid LNG turbine configuration (power plant configuration 2) has significantly lower overall emissions, particularly $\mathrm{CH}_{4}$ emissions, when compared to the other two configurations. The effect of reduced $\mathrm{CH}_{4}$ emissions is highlighted when taking the global warming potential (GWP) of $\mathrm{CH}_{4}$ into account. According to the Intergovernmental Panel on Climate Change (IPCC), $\mathrm{CH}_{4}$ has a GWP of 25, meaning that the global warming effects of 1 tonne of $\mathrm{CH}_{4}$ emissions are the equivalent of 25 tonnes of $\mathrm{CO}_{2}$ (Intergovernmental Panel on Climate Change, 2007). To demonstrate the effects of reduced $\mathrm{CH}_{4}$ emissions, the combined $\mathrm{GWP}$ from $\mathrm{CO}_{2}$ and $\mathrm{CH}_{4}$ is summarised in Table 11.

Table 11 Annual combined GWP

\begin{tabular}{|l|l|l|l|}
\hline Configuration & Hybrid Diesel & $\begin{array}{l}\text { Hybrid LNG } \\
\text { turbine }\end{array}$ & Reference power plant \\
\hline Annual combined GWP (tonnes) & 86250.7 & 53742.34 & 87277.23 \\
\hline
\end{tabular}

Tables 10 and 11 jointly show that the emissions from the hybrid diesel configuration are closer to the reference power plant compared to the hybrid LNG turbine. As can be understood from Tables 10 and 11 , if the second power plant configuration (hybrid LNG turbine) is implemented to the ferry in question, the emissions from the ship will be the lowest compared to the other two alternatives. Safety issues should also be carefully considered with the use of LNG as fuel. In addition, the usage of LNG as fuel is quite a new phenomenon, and bunkering opportunities are not well established yet. Initial investment costs associated with this new technology should also be investigated thoroughly.

The effects of using batteries become apparent when looking at the emissions while the vessel is in the port for unloading and loading. Whereas the hybrid configurations utilise their batteries to operate solely on electricity and have zero emissions while in the port, the reference power plant uses its engines to produce power. Table 12 shows the annual emissions from the reference power plant configuration while the ship is in the port for unloading/loading.

Table 12 Annual emissions of the reference power plant while the ship is in the port for unloading/loading

\begin{tabular}{|l|l|}
\hline Configuration & Reference Power Plant \\
\hline Annual $\mathrm{CO}_{2}$ emissions [tonnes] & 239.81 \\
\hline Annual $\mathrm{NO}_{x}$ emissions [kg] & 3842.0 \\
\hline Annual $\mathrm{SO}_{x}$ emissions [kg] & 157.08 \\
\hline Annual $\mathrm{PM} \mathrm{emissions} \mathrm{[kg]}_{1}$ ] & 91.50 \\
\hline Annual $\mathrm{CH}_{4}$ emissions [kg] & 4080.0 \\
\hline Annual combined GWP [tonnes] & 341.81 \\
\hline
\end{tabular}

\section{Concluding remarks and future work}

This study has focused on two aspects of designing an environmentally friendly RoPax ferry: developing a new design, and using new, green power plant technology. Various CAD- and CFDbased software packages have been used in order to achieve the aim of this research. This study has 
also demonstrated the place of CFD in the prediction of emissions from a vessel under operational conditions.

The ship design developed in this study has been compared with similar vessels that currently are in service. Even though a direct comparison between the study object and other similar ships are not conclusive, the comparison shows that the ship has been successfully designed to be more compact than the other vessels, as it is smaller in size but can carry the same amount of cargo.

The ship geometry with two skegs attached was modelled using a piece of CAD software and then imported into a CFD-based commercial software package (Star-CCM+) to predict the hull resistance in calm water conditions and to measure the Kelvin Wake behind the vessel. Before obtaining the main results, a verification study was performed for 24 knots employing the methodology proposed by Celik et al. (2008). The numerical uncertainties in the finest-grid solution for grid and time-step convergence studies were predicted to be $6.06 \%$ and $8.73 \%$, respectively. Following this, the hull resistance of the vessel was obtained for the trial conditions for various speeds using CFD. Later the total resistance of the vessel for the real operational conditions was calculated with the inclusion of the powering margin. This was followed by the determination of the power requirements of the vessel by accounting for the operational efficiencies. Based on the obtained power figures, three different power plant configurations have been suggested with a view to reveal the potential benefits of a green power plant arrangement.

The emission calculations for the suggested power plant configurations successfully indicated that there can be significant reductions of emissions by optimising the power plant. When comparing the suggested power plants to a commonly used reference power plant, the calculations reveal a significant overall reduction in emissions, and $100 \%$ reduction when the ship is in the port. The analyses clearly showed that the hybrid LNG turbine configuration, by far, provides the least GHG emissions compared to the other two power plant configurations. The reasons behind this can be attributed to the use of clean LNG fuel and the efficiency improvement of employing an extra cycle to the turbines.

The results have also shown the importance of the hybrid system in decreasing the GHG emissions. Investigation into the performance of the hybrid engine is required in order to find the most optimised usage such that the system is producing the minimum emission. For this purpose, the study should be extended to investigate different engine usages, such as $50 \%$ diesel engine $+50 \%$ battery, only battery, only diesel engine, $70 \%$ diesel engine $+30 \%$ battery. This study should also be extended to optimise the operational modes of the hybrid power system, as this will also have a notable reduction on ship emissions.

This paper has provided a useful groundwork for further investigations in this field of research. Given that cost estimations are a large and challenging topic requiring a different area of expertise, this part 
of the research was left as a future study. This would certainly help designers and practitioners to understand whether the proposed power plant is viable to invest in. 


\section{ACKNOWLEDGEMENTS}

The results were obtained using the EPSRC funded ARCHIE-WeST High Performance Computer (www.archie-west.ac.uk). EPSRC Grant no. EP/K000586/1. The authors would like to thank Miss Holly Yu for her help with the final proofreading. 


\section{REFERENCES}

American Bureau of Shipping (ABS) (2015). $\mathrm{SO}_{\mathrm{x}}$ Scrubber Ready Vessels. Houston. Retrieved from http://ww2.eagle.org/content/dam/eagle/rules-andguides/current/design_and_analysis/219_soxscrubberreadyvessels/SOx_Scrubber_Rea dy_Guide_e.pdf

Ammar, N.R, Farag, A.I. (2016). CFD modelling of syngas combustion and emissions for marine gas turbine applications. Polish Maritime Research, 23(3), 39-49. DOI: 10.1515/pomr-2016-0030

ASEA Brown Boveri (ABB) (2014). Shaft generator drive for marine. Retrieved from https://library.e.abb.com/public/439229cbf491151c48257d150041783d/17163_Shaft_ generator_drive_for_marine_EN_3AUA0000165329_RevA_lowres.pdf

Besnard, E., Schmitz, A., Hefazi, H., Shinde, R., (2007). Constructive Neural Networks and Their Application to Ship Multidisciplinary Design Optimisation. Journal of Ship Research, 51, 297-312.

Campana, E., Peri, D., Tahara, Y., Stern, F. (2006). Shape optimisation in ship hydrodynamics using computational fluid dynamics. Computer Methods in Applied Mechanics and Engineering, 196, 634-651. DOI: 10.1016/j.cma.2006.06.003

CD-Adapco (2016). User guide STAR-CCM+ Version 11.0.2.

Celik, I.B., Ghia, U., Roache, P.J., Freitas, C.J. (2008). Procedure for estimation and reporting of uncertainty due to discretization in CFD applications. Journal of Fluids Engineering-Transactions of the ASME, 130(7), 078001.

Choi, J., Yoon, S.B. (2009). Numerical simulations using momentum source wave-maker applied to RANS equation model. Coastal Engineering, 56(10), 1043-1060. DOI: 10.1016/j.coastaleng.2009.06.009.

Corbett, J.J., Wang, H., Winebrake, J.J. (2009). The effectiveness and costs of speed reductions on emissions from international shipping. Transportation Research Part D, 14, 593-598. DOI: 10.1016/j.trd.2009.08.005

Cosner, R.R., Oberkampf, W.L., Rumsey, C.L., Rahaim, C.P., Shih, T.I-P. (2006). AIAA Committee on standards for computational fluid dynamics: Status and plans. In: Proceedings of 44th Aerospace Sciences Meeting and Exhibit, Reno, Nevada.

Demirel, Y.K., Turan, O., Incecik, A. (2017). Predicting the effect of biofouling on ship resistance using CFD. Applied Ocean Research, 62, 100-118. DOI: 10.1016/j.apor.2016.12.003.

DNV GL. (2015a). In focus - the future is hybrid - a guide to use batteries in shipping. Hamburg, Germany. Retrieved from http://www.dnvglsource.com/assets/documents/src/in_focus_the_future_is_hybrid.pdf

DNV GL. (2015b). In focus - LNG as ship fuel. Hamburg, Germany. Retrieved from https://www.dnvgl.com/Images/DNV\%20GL_LNG\%20Report\%202015_tcm824903.pdf

Enger, S., Peric, M., Peric, R. (2010). Simulation of flow around KCS-hull. In: Proceedings from Gothenburg 2010-A Workshop on Numerical Ship Hydrodynamics, Gothenburg. 
Environmental Protection Authority (EPA) (2010). Control of Emissions from New Marine Compression-Ignition Engines at or Above 30 Litres per 409 Cylinder; Final Rule. Federal Register/Rules and Regulations. 75(83), 30 April 2010.

European Maritime Safety Agency (EMSA) (2015). EMSA Consolidated Annual Activity Report. Retrieved from www.emsa.europa.eu/emsadocuments/latest/download/4180/2746/23.html

General Electric Marine. (2013). GE Marine's non-SCR diesel technology requires no aftertreatment. Retrieved from http://media.getransportation.com/sites/default/files/L250V250\%20EPAT4i\%20IMOT III\%20Engine \%20Factsheet.pdf

GTT, CMA CGM, DNV GL (2015). The Piston Engine Room Free Efficient Containership (PERFECt). DNV GL, Hamburg, Germany. Retrieved from https://www.dnvgl.com/Images/Gas\%20Tech\%20W\%C3\%BCrsig_201510_web_tcm8-45310.pdf

Guo, B. J., Deng, G. B., Steen, S. (2013) Verification and validation of numerical calculation of ship resistance and flow field of a large tanker, Journal of Ships and Offshore Structures, Vol. 8, No.1, pp. 3-14.

Hand, M. (2015). Scandlines aims for zero emissions, battery-powered fleet by 2018. Sea trade Maritime News. Retrieved from http://www.seatrademaritime.com/news/europe/scandlines-aims-for-zero-emissions-battery-powered-fleetby-2018.html

He, J., Hannapel, S., Vlahopoulos, N., (2011). Multidisciplinary design optimisation of ship hull forms using metamodels. Proceedings of the ASME 2011 International Design Engineering Technical Conferences \& Computers and Information in Engineering Conference, August 29-31, 2011, Washington, DC, USA.

Hochkirck, K., Bertram, V., (2010). Options for fuel saving for ships. Article accessed via Researchgate, retrieved from https://www.researchgate.net/publication/228446521_Options_for_Fuel_Saving_for_S hips

Hochkirck, K., Mallol, B., (2013). On the importance of full-scale CFD simulations for ships. In: Proceedings of the 12th International Conference on Computer Applications and Information Technology in the Maritime Industries (COMPIT 2013), Cortona, Italy, pp. 85-95.

Huber, J. (2016). E-mail correspondence dated 07.07.2016.

Igoe, B.M., Engelbert, C., Scott, K., Charlton, S., Mapleston, T. (2011). Design and early development of the SGT-300 twin shaft gas turbine. $19^{\text {th }}$ Symposium of the Industrial Application of Gas Turbines Committee, Banff, Alberta, Canada. Paper No. 11-IAGT201.

Intergovernmental Panel on Climate Change (2007). Global Warming Potentials. Intergovernmental Panel on Climate Change.

International Chamber of Shipping (ICS) (2014). Shipping, world trade and the reduction of CO2emissions. 
International Maritime Organisation (IMO) (2009). Second IMO GHG Study. April 2009. London, UK.

International Maritime Organisation (IMO) (2012). Resolution MEPC.212 (63) Guidelines on the method of calculation of the attained energy efficiency design index (EEDI) for new ships. MEPC 63/23, London: International Maritime Organization; 2012.

International Maritime Organisation (IMO) (2014). MARPOL Annex VI.

International Maritime Organisation (IMO) (2015). Third IMO Greenhouse Gas Study 2014. London.

International Towing Tank Conference (ITTC) (2005). Testing and Extrapolation Methods, Propulsion, Performance, Predicting Power Margins, Revision 00. Retrieved from ittc.info/media/1836/75-02-03-015.pdf

International Towing Tank Conference (ITTC) (2011). Practical Guidelines for Ship CFD Application. Retrieved from http://ittc.info/downloads/Archive\%20of\%20recommended\%20procedures/2011\%20R ecommended\%20Procedures/7.5-03-02-03.pdf

Kilpinen, P. (2010). Optimization of a simplified sub-model for NO emission prediction by CFD in large 4-stroke marine diesel engines. Fuel Processing Technology, 91, 218228. DOI: 10.1016/j.fuproc.2009.10.001.

Kim, S.O, Ock, Y.B., Heo, J.K., Park, J.C., Shin, H.S., Lee, S.K. (2014). CFD simulation of added resistance of ships in head sea for estimating energy efficiency design index. OCEANS 2014 - TAIPEI, Taipei, pp. 1-5. DOI: 10.1109/OCEANSTAIPEI.2014.6964578.

Kim, S.P., Lee, H.H. (2011). Fully nonlinear seakeeping analysis based on CFD simulations. In: Proceedings of the 21st International Offshore and Polar Engineering Conference, Hawaii, USA, pp. 970-974.

Kristiansen, H. O. (2012). Energy demand and exhaust gas emissions of marine engines. Technical University of Denmark. Project no. 2010-56, Work package 2, Report no. 05.

Lewis, E.V. (1988). Principles of Naval Architecture, second revision. Volume II: Resistance, Propulsion and Vibration. The Society of Naval Architecture and Marine Engineers, Jersey City, USA.

Lindstad, H.E., Sandaas, I. (2016. Emission and fuel reduction for offshore support vessels through hybrid technology". Journal of Ship Production and Design, 32, 195-205. DOI: $10.5957 /$ JSPD.32.4.150006.

MAN (2011). Basic Principles of Ship Propulsion. Retrieved from, https://marine.man.eu/docs/librariesprovider6/propeller-aftship/basic-principles-ofpropulsion.pdf?sfvrsn $=0$

MAN Diesel (n.d.). Diesel-electric Propulsion Plants. Retrieved from https://marine.man.eu/docs/librariesprovider6/marine-broschures/diesel-electricdrives-guideline.pdf?sfvrsn $=0$

Mizzi, K., Demirel, Y.K., Banks, C., Turan, O., Kaklis, P., Atlar, M. (2017). Design optimisation of Propeller Boss Cap Fins for enhanced propeller performance. Applied Ocean Research, 62, 210-222. DOI: 10.1016/j.apor.2016.12.006. 
Ozdemir, Y.H., Barlas, B., Yilmaz, T., Bayraktar, S. (2014). Numerical and experimental study of turbulent free surface flow for a fast ship model. Brodogradnja (Shipbuilding), 65 (1) (2014), pp. 39-54.

Pike K., Butt N., Johnson D., Walmsley S. (2011). Global Sustainable Shipping Initiatives: Audit and Overview. A Report for WWF.

Querard, A.B.G., Temarel, P., Turnock, S.R. (2008). Influence of viscous effects on the hydrodynamics of ship-like sections undergoing symmetric and anti-symmetric motions, using RANS. Proceedings of the ASME 27th International Conference on Offshore Mechanics and Arctic Engineering (OMAE), Estoril, Portugal, Vol. 5, pp. 683-692.

Richardson, L.F. (1911). The approximate arithmetical solution by finite differences of physical problems involving differential equations, with an application to the stresses in a Masonry dam. Philosophical Transactions of the Royal Society of London Series A-Containing Papers of a Mathematical or Physical Character, 210, 307-357.

Roache, P.J. (1998). Verification and validation in computational science and engineering, Albuquerque: Hermosa Publishers.

Roy, C.J., Blottner, F.G. (2001). Assessment of one- and two-equation turbulence models for hypersonic transitional flows. Journal of Spacecraft and Rockets, 38(5), 699-710.

Rozman, S. (2009). Wake pattern of a boat. Ljubljana. University of Ljubljana, Faculty of Mathematics and Physics, Department of Physics. Seminar 2008/09. Retrieved from http://www.prirodopolis.hr/daily_phy/pdf/speed.pdf

Shen, Z., Wan, D. (2012). RANS computations of added resistance and motions of ships in head waves. In: Proceedings of 22nd International Offshore and Polar Engineering Conference, Rhodes, Greece, pp. 1096-1103.

Simonsen, C.D., Otzen, J.F., Joncquez, S., Stern, F. (2013). EFD and CFD for KCS heaving and pitching in regular head waves. Journal of Marine Science and Technology, 18 (4) (2013), pp. 435-459.

Stern, F., Wilson, R., Shao, J. (2006). Quantitative V\&V of CFD simulations and certification of CFD codes. International Journal for Numerical Methods in Fluids; 50(11), 13351355.

Tezdogan, T., Demirel, Y. K., Kellett, P., Khorasanchi, M., Incecik, A., Turan, O. (2015). Full-scale unsteady RANS CFD simulations of ship behaviour and performance in head seas due to slow steaming. Ocean Engineering, 97, 186-206. DOI: 10.1016/j.oceaneng.2015.01.011.

Tezdogan, T., Incecik, A., Turan, O. (2016). Full-scale unsteady RANS simulations of vertical ship motions in shallow water. Ocean Engineering, 123, 131-145. DOI: 10.1016/j.oceaneng.2016.06.047.

Theotokatos, G., Tzelepis, V. (2015). A Computational study on the performance and emissions parameters 450 mapping of a ship propulsion system. Proc. IMechE Part M: J. Eng. Mar. Environ. 229, 58-76.

Vyselaar, D., Klaptocz, V., Calisal, S.M. (2007) A numerical approach to resistance reduction of displacement vessels using parabolic waterlines. Ships and Offshore Structures, 2:2, 127-136. DOI: 10.1080/17445300701430176.

Welch, M. (2016). E-mail correspondence dated 22.07.2016. 
Welch, M., Kavli, P. (2013). A Novel Solution to Deepwater Logistical Challenges: Fast Supply Shuttles and High Bollard Pull AHTS. Rio de Janeiro, Brazil: Siemens Industrial Turbomachinery Ltd.

Xing, T., Stern, F. (2010). Factors of safety for Richardson Extrapolation. Journal of Fluids Engineering-Transactions of the ASME 2010, 132(6), 061403.

Zagkas, V. K., Pratikakis, G. N. (2012). Specifications of Cargo and Passenger Ships. The FAROS Project, Deliverable report 3.1. Supported by European Commission's FP7 Programme. Retrieved from: faros-project.eu/public/Deliverable-D3.1-FINAL.pdf 


\section{APPENDIX}

\section{Emission Calculations}

\section{Power plant configuration 1: 4x GE 16V250}

Max output per engine

Total installed power ( $4 \mathrm{x}$ engine)

$4650 \mathrm{~kW}$

$18600 \mathrm{~kW}$

BSFC at MRC

Max speed

20.1 knots

Cruising speed

Power requirement at cruise speed

19.5 knots

$17800 \mathrm{~kW}$

Onboard usage

$800 \mathrm{~kW}$

Trip duration at cruise speed

15.385 hours

$\mathrm{CO} 2$ emission MDO

Sulfur content MDO

SOx emission MDO

Nox emissions GE TIER3

Emission of particulates (PM)

Methane slip

3.206 tonne/tonne oil

$0.1 \%$

$2.1 \mathrm{~kg} /$ tonne oil

$2.1 \mathrm{~g} / \mathrm{kWh}$

$0.269 \mathrm{~g} / \mathrm{kWh}$

$12 \mathrm{~g} / \mathrm{kWh}$

$3348 \mathrm{~kg} / \mathrm{h}$

51.508 tonnes

165.134 tonnes

$108.166 \mathrm{~kg}$

$600.923 \mathrm{~kg}$

$77.013 \mathrm{~kg}$

$3433.846 \mathrm{~kg}$

340

17512.615 tonnes

56145.445 tonnes

36.776 tonnes

204.314 tonnes

26.184 tonnes

1167.508 tonnes

1

25

56145.445 tonnes

29187.692 tonnes

85333.137 tonnes
Source: IMO, 2009

Source: MARPOL Annex VI (IMO, 2014)

Source: Kristiansen, 2012

Source: MARPOL Annex VI (IMO, 2014)

Source: Kristiansen, 2012

Source: Welch and Kavli, 2013

Annual GWP CO2

Annual GWP Methane

Combined GWP 


\section{Power plant configuration 2: Siemens SGT-300 LNG Turbines}

Max power output

Total installed power $2 \mathrm{x}$ Turbine

BSFC at max rating

Onboard usage

Trip duration at cruise speed

$\mathrm{CO} 2$ emission $\mathrm{LNG}$

Sulfur content MDO

SOx emission MDO

Nox emissions

Emission of particulates (PM)

Methane slip

Fuel consumption at cruise speed

Fuel consumption per trip

$\mathrm{CO} 2$ emissions per trip

SOx emissions per trip

NOx emissions per trip

PM emissions per trip

Methane slip per trip

Annual trips

Annual fuel consumption

Annual CO2 emissions

Annual SOx emissions

Annual NOx emissions

Annual PM emissions

Annual methane slip

GWP factor $\mathrm{CO} 2$

GWP factor Methane

Annual GWP CO2

Annual GWP Methane

Combined GWP
$9200 \mathrm{~kW}$

$23920 \mathrm{~kW}$

$0.170 \mathrm{~kg} / \mathrm{kWh}$

21.5 knots

21.3 knots

$22920 \mathrm{~kW}$

$1000 \mathrm{~kW}$

Source: Igoe et al., 2011

Source: Welch, 2016

14.085 hours

$\begin{array}{cl}2.75 \text { tonne/tonne oil } & \text { Source: IMO, 2009 } \\ 0 \% & \text { Source: Welch, 2016 } \\ 0 \mathrm{~kg} / \text { tonne oil } & \text { Source: Welch, 2016 } \\ 0.4 \mathrm{~g} / \mathrm{kWh} & \text { Source: Welch, 2016 } \\ 0 \mathrm{~g} / \mathrm{kWh} & \text { Source: Welch, 2016 } \\ 0.1 \mathrm{~g} / \mathrm{kWh} & \text { Source: Welch and Kavli, } 2013\end{array}$

$4059.224 \mathrm{~kg} / \mathrm{h}$

57.172 tonnes

157.223 tonnes

$0 \mathrm{~kg}$

$134.761 \mathrm{~kg}$

$0 \mathrm{~kg}$

$33.690 \mathrm{~kg}$

340

19438.537 tonnes

53455.978 tonnes

0 tonnes

45.819 tonnes

0 tonnes

11.455 tonnes

1

25

53455.978 tonnes

286.366 tonnes

53742.344 tonnes 


\section{Power plant configuration 3: Reference power plant (Conventional propulsion)}

Total installed power

BSFC at MCR

BSFC at port

Cruising speed

Power requirement at cruise speed

Onboard usage

Trip duration at cruise speed

Duration of port visit

$\mathrm{CO} 2$ emission MDO

Sulfur content MDO

SOx emission MDO

Nox emissions

Emission of particulates (PM)

Methane slip

Fuel consumption at cruise speed per hour

Fuel consumption at port per hour

Fuel consumption per trip

Fuel consumption at port

$\mathrm{CO} 2$ emissions per trip

$\mathrm{CO} 2$ emissions at port

SOx emissions per trip

SOx emissions at port

NOx emissions per trip

NOx emissions at port

PM emissions per trip

$\mathrm{PM}$ emissions at port

Methane slip per trip

Methane slip at port

Price of fuel

Total fuel cost per trip

Annual trips

Annual fuel consumption

Annual CO2 emissions

Annual SOx emissions

Annual NOx emissions

Annual PM emissions

Annual methane slip

Annual fuel cost

Annual CO2 emissions on port

Annual SOX emissions in port

Annual NOX emissions in port

Annual PM emissions in port

Annual methane slip in port

Combined annual GWP in port

GWP factor $\mathrm{CO} 2$

GWP factor Methane

Annual GWP CO2

Annual GWP Methane

Combined annual GWP
18400

$0.185 \mathrm{~kg} / \mathrm{kWh}$

$0.22 \mathrm{~kg} / \mathrm{kWh}$

19.7 knots

$17900 \mathrm{~kW}$

$500 \mathrm{~kW}$

15.228 hours

2 hours

3.206 tonne/tonne oil Source: IMO, 2009

$0.1 \%$

Source: MARPOL Annex VI (IMO, 2014)

$2.1 \mathrm{~kg} /$ tonne oil $\quad$ Source: Kristiansen, 2012

$11.3 \mathrm{~g} / \mathrm{kWh}$

$0.269 \mathrm{~g} / \mathrm{kWh}$

$12 \mathrm{~g} / \mathrm{kWh}$

Source: MARPOL Annex VI (IMO, 2014)

Source: Kristiansen, 2012

Source: Welch et al., 2013

$3404 \mathrm{~kg} / \mathrm{h}$

$110 \mathrm{~kg} / \mathrm{h}$

52.058 tonnes

$220 \mathrm{~kg}$

166.897 tonnes

$705.32 \mathrm{~kg}$

$109.783 \mathrm{~kg}$

$0.462 \mathrm{~kg}$

$3177.594 \mathrm{~kg}$

$11.3 \mathrm{~kg}$

$75.680 \mathrm{~kg}$

$0.269 \mathrm{~kg}$

$3374.437 \mathrm{~kg}$

$12 \mathrm{~kg}$

$400 \$ /$ tonne

$20823.025 \$$

340

17699.572 tonnes

56744.826 tonnes

37.326 tonnes

1080.382 tonnes

25.731 tonnes

1147.308 tonnes

$7.080 \mathrm{M} \$$

239.809 tonnes

$157.080 \mathrm{~kg}$

$3842 \mathrm{~kg}$

$91.504 \mathrm{~kg}$

$4080 \mathrm{~kg}$

341.809

1

25

56744.826 tonnes

28682.711 tonnes

85427.537 tonnes 